\title{
Contribuição ao conhecimento de Cosmarium Corda ex Ralfs (Desmidiaceae, Zygnematophyceae) para a Bahia e o Brasil
}

\author{
Ivania Batista de Oliveira ${ }^{1,3}$, Carlos Eduardo de Mattos Bicudo ${ }^{2}$ e Carlos Wallace do Nascimento Moura ${ }^{1}$
}

Recebido: 04.01.2010; aceito: 05.08.2010

\begin{abstract}
Contribution to the knowledge of Cosmarium Corda ex Ralfs (Desmidiaceae, Zygnematophyceae) to Bahia and Brazil). This study aimed to identify the taxa belonging to the genus Cosmarium present in two Environmental Protection Areas of the coastal plain of the northern Bahia, and contribute to the knowledge of its taxonomic composition and geographic distribution in Bahia State, Brazil. Samples were collected during the Summer (January to March 2007) and Winter (June to August 2007) using plankton net $20 \mu \mathrm{m}$ size and fixed immediately in Transeau solution. Qualitative analysis and illustrations were conducted with the aid of an optical microscope and digital camera attached. Forty-three taxa were recorded, of these, three species and two varieties are new records for Brazil, and 28 species and three varieties are new records for the State of Bahia.
\end{abstract}

Key words: desmids, phytoplankton, taxonomy

RESUMO - (Contribuição ao conhecimento de Cosmarium Corda ex Ralfs (Desmidiaceae, Zygnematophyceae) para a Bahia e o Brasil). Este estudo teve como objetivo identificar os táxons do gênero Cosmarium presentes em duas Áreas de Proteção Ambiental da planície litorânea do norte da Bahia e contribuir para o conhecimento da biodiversidade do estado, bem como ampliar o conhecimento da distribuição dos táxons identificados na Bahia e no Brasil. O levantamento taxonômico foi baseado em coletas realizadas no verão (janeiro a março de 2007) e no inverno (junho a agosto de 2007). As amostras foram obtidas através de rede de plâncton com $20 \mu \mathrm{m}$ de abertura de malha e imediatamente fixadas em solução de Transeau. As análises qualitativas e ilustrações foram obtidas utilizando microscópio óptico binocular e máquina fotográfica digital acoplada. Foram registrados 43; táxons, destes, três espécies e duas variedades são ocorrências novas para o Brasil, e 28 espécies e três variedades são novos registros para o estado da Bahia.

Palavras-chave: desmídias, fitoplâncton, taxonomia

\section{Introdução}

Os organismos pertencentes à classe Zygnematophyceae, conhecidos como desmídias lato sensu, constituem um grupo relevante nos ambientes aquáticos continentais, pela alta diversidade morfológica, riqueza específica e grande importância ecológica (Brook 1981, Wehr \& Sheat 2003).

Entre as desmídias, o gênero Cosmarium Corda ex Ralfs é caracterizado por apresentar células em geral solitárias, de vida livre, com seno mediano variando de uma depressão rasa e aberta até uma fenda linear e fechada; vista apical elíptica, oblonga ou reniforme e raramente circular; semicélula variando de esféricas a subpiramidais ou até cônicas; parede celular lisa, pontuada, granulada, escrobiculada, com dentículos mais ou menos cônicos ou combinações desses elementos; podem também ocorrer poros de mucilagem; um ou dois cloroplastídios axiais por semicélula ou, em alguns casos, até oito deles, sendo estes parietais.

$\mathrm{Na}$ Bahia há poucos estudos sobre a biodiversidade de desmídias, o que não deixa de ser extensivo ao gênero Cosmarium. Informações sobre estas algas no estado estão sintetizadas em três trabalhos: Förster (1964), Martins \& Bicudo (1987) e Bicudo \& Martins (1989).

Este trabalho teve por objetivo documentar as espécies de Cosmarium de duas áreas de Proteção Ambiental, litoral norte do estado da Bahia, vizando

1. Universidade Estadual de Feira de Santana, Departamento de Ciências Biológicas, Programa de Pós-Graduação em Botânica, Laboratório de Ficologia, Av. Transnordestina s/n, Novo Horizonte, 44036-900 Feira de Santana, BA, Brasil

2. Instituto de Botânica, Seção de Ecologia, Av. Miguel Estéfano, 3687, 04301-902 São Paulo, SP, Brasil

3. Autor para correspondência: ivboliveira@gmail.com 
minimizar a lacuna existente sobre o conhecimento do gênero no estado. São apresentadas descrições, comparações com táxons afins e ampliada a distribuição geográfica das espécies no Brasil.

\section{Material e métodos}

A área de estudo localiza-se no município de Camaçari, Região Metropolitana de Salvador, litoral norte da Bahia e abrange a APA Lagoas de Guarajuba, com área de 230 ha e a APA Rio Capivara, com área de 1.800 ha (figura 1 ).

O material foi coletado em dois períodos, verão (jan-mar/2007) e inverno (jun-ago/2007), totalizando 60 unidades amostrais, sendo 30 estações arbitrárias na APA Lagoas de Guarajuba e 30 na APA Rio Capivara. A coleta do material foi feita de acordo com os métodos usuais empregados nos estudos de taxonomia de microalgas continentais (Bicudo \& Menezes 2006).

Os limites métricos das populações foram aferidos através de ocular micrométrica e as fotomicrografias obtidas com câmara fotográfica digital ambos acoplados ao microscópio óptico, e as identificações das espécies baseadas em literatura especializada. O sistema de classificação adotado segue Brook (1981).

As amostras foram preservadas em solução de Transeau preparada conforme Bicudo \& Menezes (2006) e tombadas na coleção líquida do Herbário da Universidade Estadual de Feira de Santana (HUEFS).

\section{Resultados e Discussão}

O levantamento florístico do gênero Cosmarium nas duas APAs estudadas registrou a ocorrência de 43 táxons. Destes, três espécies e duas variedades estão sendo registrados pela primeira vez para o Brasil e, 28 espécies e três variedades são novas ocorrências para o estado da Bahia.

O gênero está representado na área estudada por 43 táxons.

Chave para identificação das espécies de Cosmarium estudadas

1. Parede celular lisa ou finamente pontuada

2. Parede celular lisa

3. Células $<20 \mu \mathrm{m}$ compr.

4. Margem apical convexa a quase reta

C. regnesii var. regnesii

4. Margem apical retusa

5. Semicélula subquadrangular C. subretusiforme

5. Semicélula trapeziforme C. arctoun var. minor

3. Células $>20 \mu \mathrm{m}$ compr.

6. Margem lateral ondulada

7. Células 1,2-1,3 vezes mais longas que largas

C. moerlianum var. brasiliense

7. Células 1,5-1,7 vezes mais longas que largas

C. impressulum

6. Margem lateral aconcavada

8. Semicélula subcircular

C. exiguum var. exiguum f. incrassatum

8. Semicélula trilobada C. trilobulatum var. abscissum

2. Parede celular pontuada

9. Células 20-75 $\mu \mathrm{m}$ compr.

10. Margem lateral arredondada ou convexa

11. Margem lateral arredondada C. pseudoconnatum var. pseudoconnatum

11. Margem lateral convexa

12. Células 30-40 $\mu \mathrm{m}$ compr.

13. Semicélula subcircular

C. contractum var. rotundatum

13. Semicélula piramidal-truncada C. ocelatum var. incrassatum

12. Células 60-75 $\mu \mathrm{m}$ compr.

14. Semicélula piramidal-trundada, ápice truncado

C. pseudopyramidatum var. pseudopyramidatum f. pseudopyramidatum

14. Semicélula trapeziforme, arredondada, ápice amplamente arredondado 
10. Margem lateral leve a acentuadamente côncava

15. Margem lateral acentuadamente côncava

16. Seno mediano aberto C. depressum var. elevatum

16. Seno mediano fechado C. regulare

15. Margem lateral levemente côncava

17. Margem apical retusa

C. granatum var. concavum

17. Margem apical arredondada

18. Semicélulas subquadrangulares a amplamente arredondada

C. contractum var. contractum

18. Semicélula de outra forma

19. Face da semicélula com 1 concavidade de cada lado

19. Face da semicélula sem qualquer concavidade

20. Célula de contorno elíptico

C. pseudovariolatum var. incrassatum

20. Célula de contorno subcircular

21. Semicélula semicircular

C. pseudopyramidatum var. rotundatum

21. Semicélula elíptica

C. galeritum var. subtumidum

9. Células $>90 \mu \mathrm{m}$ compr.

22. Margem lateral convexa

C. obsoletum var. obsoletum

22. Margem lateral arredondada

23. Células 1,7-1,8 vezes mais longas que largas

23. Células 1,2-1,4 vezes mais longas que largas

24. Semicélula triangular-arredondada

24. Semicélula elíptica .................................................. C. pach

C. securiforme var. brasiliense

C. pseudopyramidatum var. maximum

1. Parede celular ornamentada com verrugas, granul
25. Parede celular com espinhos e escobículos

26. Parede celular ornamentada com espinhos curtos

C. lagoense var. amoebum

26. Parede celular com escrobículos

C. variolatum var. variolatum

25. Parede celular ornamentada com verrugas e grânulos

27. Parede celular ornamentada com grânulos

28. Margem apical convexa ou arredondada

29. Margem apical convexa

C. excavatum var. excavatum

29. Margem apical arredondada......

C. margaritatum var. margaritatum f. margaritatum

28. Margem apical retusa ou truncada

30. Margem apical levemente truncada C. monomazum var. dimazum f. brasiliense

30. Margem apical retusa

31. Margem lateral côncava

C. furcatospermum

31. Margem lateral arredondada

C. quadrifarium var. quadrifarium f. quadrifarium

27. Parede celular ornamentada com verrugas

32. Célula elíptica

33. Margem lateral arredondada .....

C. blyttii var. blyttii

33. Margem lateral de outra forma

34. Margem lateral convexa

34. Margem lateral côncava

35. Semicélula ovalada

35. Semicélula trapeziforme

C. quadrum var. quadrum

C. conspersum var. conspersum f. conspersum

32. Célula quadrangular, subquadrangular ou subcircular

36. Célula quadrangular

C. vitiosum var. vitiosum

36. Células subquadrangulares ou subcirculares

37. Células subcirculares

C. quadrum var. minus

37. Células subquadrangulares

38. Semicélulas reniformes 
39. Células $32-40 \mu \mathrm{m}$ compr.

C. ornatum var. ornatum

39. Células 62-75 $\mu \mathrm{m}$ compr.

C. reniforme var. reniforme

38. Semicélulas oblongas.

40. Margem apical retusa

C. gemminatum var. scottii

40. Margem apical arredondada

41. Células ca. 1,4 vezes mais largas que longas

C. sphalerostichum var. sphalerostichum $\mathrm{f}$. bituberculatum

41. Células tão longas quanto largas

42. Margem apical ornada com 1 série de verrugas cuneiformes

42. Margem apical arredondada

C. ornatum var. pseudolagoense C. orthostichum var. pumilum

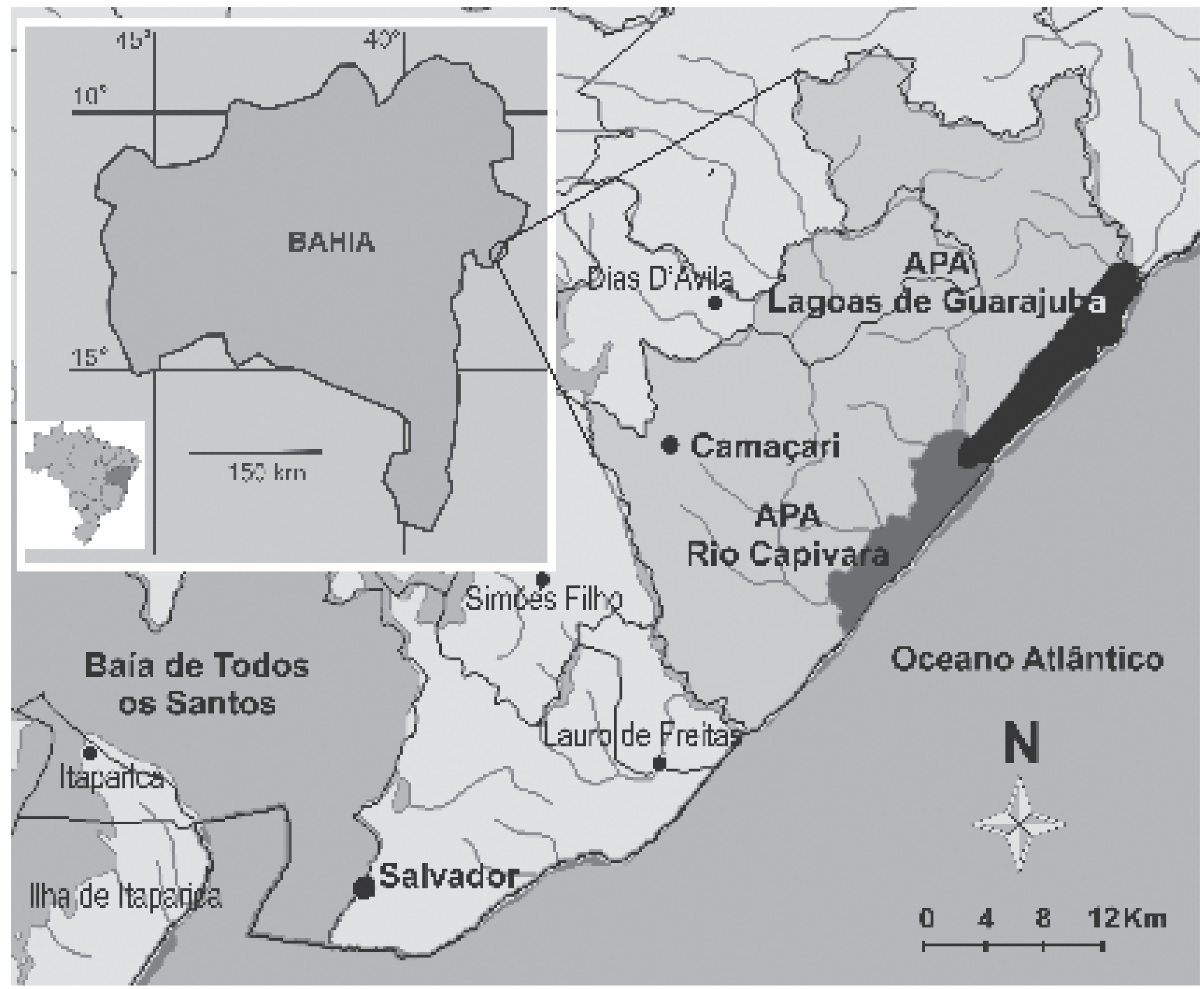

Figura 1. Mapa de localização do estado da Bahia, município de Camaçari e as duas Áreas de Proteção Ambiental - APA Rio Capivara e APA Lagoas de Guarajuba.

Figure 1. Map of the Bahia state and Camaçari city and two areas of Environment Protection Areas - APA Rio Capivara and APA Lagoas de Guarajuba. 
Cosmarium arctoum Nordst. var. minor West, Linn. Soc. Journ. Bot. 29 (199/200): 162, pl. 24, fig. 24. 1892.

Figura 2

Célula ca. 1,2 vezes mais longa que larga, 12,514,5 $\mu \mathrm{m}$ compr., 10-12 $\mu \mathrm{m}$ larg., istmo 6-8 $\mu \mathrm{m}$ larg., contorno aproximadamente retangular, constrição mediana leve, seno mediano aberto, amplo; semicélula trapeziforme, margens laterais côncavas, margem apical retusa, 1 concavidade no meio; parede celular hialina a levemente acastanhada, lisa; cloroplastídio axial; pirenóide não observado.

Material examinado: BRASIL. BAHIA: Camaçari, APA Rio Capivara, 12-I-2007, I.B. Oliveira \& I.S. Oliveira s.n. (HUEFS125518); 9-III-2007, I.B. Oliveira et al. s.n. (HUEFS125545, HUEFS125551); 20-VII-2007, I.B. Oliveira et al. s.n. (HUEFS125586); 25-VIII2007, I.B. Oliveira et al. s.n. (HUEFS125603).

Distribuição geográfica no Brasil: primeiro registro da variedade para o país.

A var. minor West difere da típica da espécie por apresentar medidas celulares menores e margens laterais mais côncavas e mais expandidas lateralmente. É uma variedade de identificação relativamente fácil, dada sua circunscrição bem definida. Croasdale \& Flint (1988) identificaram exemplares de Cosmarium arctoum, cujos limites métricos celulares da variedade típica da espécie $(9-22 \times 7-18 \mu \mathrm{m})$ recobrem os limites propostos originalmente para a var. minor West $(9-10 \times 12,5$ $\mu \mathrm{m})$.

Cosmarium blyttii Wille var. blyttii, Forh. Vidensk.

Selsk. Chistiania 11: 25, pl. 1, fig. 7. 1880. Figuras 3-4

Célula 1,2-1,3 vezes mais longa que larga, 17,5$19 \mu \mathrm{m}$ compr., 14-14,5 $\mu \mathrm{m}$ larg., istmo 3,5-5,5 $\mu \mathrm{m}$ larg., contorno subquadrático, constrição mediana profunda, seno mediano linear, fechado; semicélula oblonga, margens laterais arredondadas, crenadas, margem apical retusa, crenada, parede celular hialina; cloroplastídio axial; pirenóide 1, central.

Material examinado: BRASIL. BAHIA: Camaçari, APA Lagoas de Guarajuba, 12-I-2007, I.B. Oliveira \& I.S. Oliveira s.n. (HUEFS125503, HUEFS125504); 9-III-2007, I.B. Oliveira et al. s.n. (HUEFS125523, HUEFS125532, HUEFS125538, HUEFS125543); APA Rio Capivara, 12-I-2007, I.B. Oliveira \& I.S. Oliveira s.n. (HUEFS125512); 9-III-2007, I.B. Oliveira et al. s.n. (HUEFS125545, HUEFS125551, HUEFS125554, HUEFS125560, HUEFS125561).
Distribuição geográfica no Brasil: Paraná (Felisberto \& Rodrigues 2005).

Cosmarium blyttii var. blyttii é uma espécie muito comum nos corpos de águas continentais e sua identificaçãoérelativamente fácil. Morfologicamente, pode ocorrer variação, principalmente, relacionada ao número de crenulações das margens laterais e apical e ao número de grânulos que ornamentam a face de cada semicélula. Na ornamentação facial, pode aparecer apenas um grânulo central ou um anel deles.

Cosmarium conspersum Ralfs var. conspersum $f$. conspersum, Brit. Desmidieae: 101, pl. 116, fig. 4a-b. 1848.

Figura 5

Célula ca. 1,3 vezes mais longas que largas, 68-84 $\mu \mathrm{m}$ compr., 46-60 $\mu \mathrm{m}$ larg., istmo 17-22 $\mu \mathrm{m}$; de contorno elíptico, constrição mediana profunda, seno mediano abrindo no sentido das extremidades, extremidades dilatadas; semicélula ovalada, margens laterais côncavas, margem apical arredondada; parede celular hialina, verrugas distribuídas em série verticais; cloroplastídios axiais 2; pirenóides 2.

Material examinado: BRASIL. BAHIA: Camaçari, APA Lagoas de Guarajuba, 12-I-2007, I.B. Oliveira \&I.S. Oliveira, s.n. (HUEFS125503, HUEFS125504, HUEFS125505); APA Rio Capivara, 12-I-2007, I.B. Oliveira \& I.S. Oliveira s.n. (HUEFS125520); 9-III2007, I.B. Oliveira et al. s.n. (HUEFS125548); 8-VI2007, I.B. Oliveira et al. s.n. (HUEFS125571); 25VIII-2007, I.B. Oliveira et al. s.n. (HUEFS125607, HUEFS125608).

Distribuição geográfica no Brasil: primeiro registro da espécie para o país.

Cosmarium conspersum var. conspersum f. conspersum é morfologicamente próximo de C. margaritatum (Lundell) Roy \& Bisset var. margaritatum f. margaritatum, do qual difere por apresentar as verrugas distribuídas em séries diagonais, pontuações entre as verrugas e o istmo, relativamente, mais fechado. Prescott et al. (1981) e Croasdale \& Flint (1988) descrevem espécimes com medidas celulares maiores que as encontradas nesse estudo, respectivamente $82-110 \times 50-70 \mu \mathrm{m}$ e $68-110 \times 48-79 \mu \mathrm{m}$. Excetuando as medidas, os espécimes baianos concordam com as características e ilustrações apresentadas pelos autores referidos.

Cosmarium contractum Kirchner var. contractum $\mathrm{f}$. contractum, Algen Schles. 147. 1878. 
Figuras 6-8

Célula ca. 1,6-1,7 vezes mais longa que larga, 34-40 $\mu \mathrm{m}$ compr., 20-26 $\mu \mathrm{m}$ larg., istmo 8-10 $\mu \mathrm{m}$ larg., contorno ovalado, constrição mediana profunda, seno mediano aberto, amplo, istmo pouco alongado; semicélula subquadrangular a amplamente ovalada, margens laterais côncavas, margem apical arredondada; parede celular hialina a acastanhada, lisa ou finamente pontuada; cloroplastídio parietal, preenchendo todo o espaço celular; pirenóide 1, central.

Material examinado: BRASIL. BAHIA: Camaçari, APA Lagoas de Guarajuba, 12-I-2007, I.B. Oliveira \& I.S. Oliveira s.n. (HUEFS125509); 9-III-2007, I.B. Oliveira et al. s.n. (HUEFS125538); 8-VI-2007, I.B. Oliveira et al. s.n. (HUEFS125579); 20-VII-2007, I.B. Oliveira et al. s.n. (HUEFS125596); 25-VIII2007, I.B. Oliveira et al. s.n. (HUEFS125617); APA Rio Capivara, 12-I-2007, I.B. Oliveira \& I.S. Oliveira s.n. (HUEFS125520); 9-III-2007, I.B. Oliveira et al. s.n. (HUEFS125549); 8-VI-2007, I.B. Oliveira et al. s.n. (HUEFS125571); 20-VII-2007, I.B. Oliveira et al. s.n. (HUEFS125583); 25-VIII-2007, I.B. Oliveira et al. s.n. (HUEFS125607, HUEFS125608).

Distribuição geográfica no Brasil: Amazonas (Melo \& Souza 2009), Bahia (Martins \& Bicudo 1987), Paraná (Silva \& Cecy 2004, Felisberto \& Rodrigues 2008), Rio de Janeiro (Huzar \& Silva 1992).

Grönblad (1960) registrou a presença da espécie na Itália, dividindo-a em quatro grupos de exemplares a partir da estrutura do cloroplastídio que, segundo o autor, pode ser bastante diferente. Entretanto, no presente material não foram constatadas tais diferenças nos cloroplastídios. Algumas variações morfológicas foram observadas nas populações estudadas nas duas APAs, relacionadas com o contorno celular (que variou de subquadrangular até ovalado), abertura do seno (que variou desde leve até nitidamente aberto em forma de "U"), comprimento do istmo (que variou de curto a alongado) e a margem apical que, algumas vezes, se apresentou retusa e outras, arredondada.

Cosmarium contractum Kirchner var. rotundatum Borge f. rotundatum, Ark. Bot. 4: 32, pl. 2, fig. 27. 1925.

Figura 9

Célula 1,8-1,9 vezes mais longa que larga, 34$38 \mu \mathrm{m}$ compr., 18-20 $\mu \mathrm{m}$ larg., istmo 7,5-9 $\mu \mathrm{m}$ larg., contorno oblongo, constrição mediana profunda, seno mediano aberto em forma de "V"; semicélula subcircular, margens laterais lisas, convexas, margem apical retusa, lisa; parede celular hialina, pontuada; cloroplastídio e pirenóide não observados.

Material examinado: BRASIL. BAHIA: Camaçari, APA Lagoas de Guarajuba, 12-I-2007, I.B. Oliveira \& I.S. Oliveira s.n. (HUEFS125507); 9-III-2007, I.B. Oliveira et al. s.n. (HUEFS125543); 25-VIII-2007, I.B. Oliveira et al. s.n. (HUEFS125615); APA Rio Capivara, 12-I-2007, I.B. Oliveira \& I.S. Oliveira s.n. (HUEFS125516); 9-III-2007, I.B. Oliveira et al. s.n. (HUEFS125549, HUEFS125566); 20VII-2007, I.B. Oliveira et al. s.n. (HUEFS125584, HUEFS125601); 25-VIII-2007, I.B. Oliveira et al. s.n. (HUEFS125605).

Distribuição geográfica no Brasil: Amazonas (Förster 1974).

A var. rotundatum Borge difere da típica da espécie no que diz respeito ao formato da semicélula, a primeira apresenta semicélulas arredondas e a segunda ovaladas a elípticas. Cosmarium contractum var. rotundatum $\mathrm{f}$. rotundatum apresenta abundante envoltório de mucilagem que, apesar de hialino, sempre foi muito nítido nas populações analisadas. Morfologicamente, a referida variedade é muito semelhante a $C$. americanum Lagerh. e $C$. moniliforme (Turpin) Ralfs. Difere, entretanto, de $C$. americanum pela presença do espessamento na face da semicélula e de $C$. moniliforme por apresentar semicélulas menos arredondadas e medidas celulares proporcionalmente maiores.

Cosmarium depressum (Näegeli) Lundell var. elevatum Borge, Ark. Bot. 15(13): 34, pl. 3, fig. 6. $1918 \equiv$ Euastrum depressum Näegeli, Gatt. Einzel. Alg.: 114, pl. VII: C, 2. 1849.

Figura 10

Células quase tão largas quanto longas, $36-41 \mu \mathrm{m}$ compr., 33-36 $\mu$ m larg., istmo 14-16 $\mu$ m larg., contorno amplamente elíptico, constrição mediana profunda, seno mediano aberto, acutangular, dilatado na extremidade proximal; semicélula assimetricamente elíptica, margem superior arqueada, margens basais amplamente côncavas, parede celular finamente pontuada; cloroplastídio axial, 1 por semicélula; pirenóide 1, central.

Material examinado: BRASIL. BAHIA: Camaçari, APA Lagoas de Guarajuba, 09-III-2007, I.B. Oliveira et al. s.n. (HUEFS125537, HUEFS125542, HUEFS125543); 8-VI-2007, I.B. Oliveira et al. s.n. (HUEFS125581); APA Rio Capivara, 9-III-2007, I.B. Oliveira et al. s.n. (HUEFS125521, HUEFS125527, 
HUEFS125554); 25-VIII-2007, I.B. Oliveira et al. s.n. (HUEFS125603, HUEFS125608).

Distribuição geográfica no Brasil: Amazonas (Förster 1974), Pará (Grönblad 1945), São Paulo (Araújo \& Bicudo 2006).

Cosmarium depressum var. elevatum difere da variedade típica da espécie por apresentar a margem apical mais arqueada, margem basal amplamente côncava e ângulos arredondados. Borge (1918) descreveu originalmente o táxon como tendo a parede sutilmente escrobiculada, no que difere dos atuais exemplares das duas APAs do litoral baiano. Morfologicamente, $C$. depressum var. elevatum difere de $C$. phaseulos Bréb. por apresentar uma protuberância na face central da semicélula e formato da semicélula reniforme.

Cosmarium excavatum Nordst. var. excavatum, Vidensk. Meddr Naturh. Foren. Kjöbenhavn 21: 214, pl. 3, fig. 25. 1870.

Figura 11

Célula 1,3-1,8 vezes mais longa que larga, 30-34 $\mu \mathrm{m}$ compr., 16-20 $\mu \mathrm{m}$ larg., istmo 8-10 $\mu \mathrm{m}$ larg., contorno oblongo, constrição mediana rasa, seno mediano semicircular, vértice arredondado; semicélula subcircular, conjunto das margens lateral e apical 12-onduladas, 12 grânulos marginais, margem apical e laterais convexas; parede celular hialina, granulada, grânulos em vista frontal dispostos em 4-5 séries verticais, 4 grânulos por série incluindo os marginais; cloroplastídio não observado.

Material examinado: BRASIL. BAHIA: Camaçari, APA Lagoas de Guarajuba, 12-I-2007, I.B. Oliveira \& I.S. Oliveira s.n. (HUEFS125503, HUEFS125507); 9-III-2007, I.B. Oliveira et al. s.n. (HUEFS125533, HUEFS125538, HUEFS125543, HUEFS125544); APA Rio Capivara, 12-I-2007, I.B. Oliveira \& I.S. Oliveira s.n. (HUEFS125519); 9-III-2007, I.B. Oliveira et al. s.n. (HUEFS125546, HUEFS125547, HUEFS125548).

Distribuição geográfica no Brasil: Amazonas (Lopes \& Bicudo 2002), Minas Gerais (Nordstedt 1869, Borge 1918), Mato Grosso do Sul e Rio Grande do Sul (Borge 1918).

Morfologicamente, Cosmarium excavatum var. excavatum é próximo de C. isthmium West, principalmente na disposição dos grânulos em séries verticais na parede celular. Entretanto, $C$. isthmium difere por apresentar maiores dimensões celulares (40-48 $\mu \mathrm{m}$ comrp., 25-28 $\mu \mathrm{m}$ larg., istmo
11-13,5 $\mu \mathrm{m}$ larg.), parede celular com granulação mais densa e seno mediano mais profundo e fechado.

Cosmarium exiguum W. Archer var. exiguum f. incrassatum A.M. Scott \& Grönblad, Acta Soc. Sci. Fenn. 2(8): 17, pl. 8, fig. 9-10. 1957.

Figuras 12-13

Célula 1,5-1,7 vezes mais longa que larga, 21,5-23 $\mu \mathrm{m}$ compr., 12,5-14 $\mu \mathrm{m}$ larg., istmo 3,5$5 \mu \mathrm{m}$ larg., contorno oblongo, constrição mediana profunda, seno mediano linear, fechado; semicélula semicircular, margens laterais paralelas entre si, aconcavadas, margem apical retusa; parede celular hialina, lisa; cloroplastídio axial, lobulado; pirenóide 1 , central.

Material examinado: BRASIL. BAHIA: Camaçari, APA Lagoas de Guarajuba, 12-I-2007, I.B. Oliveira \& I.S. Oliveira s.n. (HUEFS125503, HUEFS125504, HUEFS125506, HUEFS125507); 9-III-2007, I.B. Oliveira et al. s.n. (HUEFS125537); APA Rio Capivara, 12-I-2007, I.B. Oliveira \& I.S. Oliveira s.n. (HUEFS125520); 9-III-2007, I.B. Oliveira et al. s.n. (HUEFS125546, HUEFS125547, HUEFS125560).

Distribuição geográfica no Brasil: Bahia (Martins \& Bicudo 1987), Pará (Grönblad 1945).

Scott \& Grönblad (1957), propuseram a f. incrassatum a partir de material coletado no estado do Missisipi, Estados Unidos da América. No mesmo trabalho, os autores caracterizaram os representantes da nova forma taxonômica unicamente por apresentar semicélulas mais subcirculares, o que foi verificado nos exemplares estudados.

Cosmarium furcatospermum West \& G.S.West, Journ. R. Microsc. Soc. 1894: 7, pl. 1, fig. 13. 1894.

Figuras 14-15

Célula ca. 1,2 vezes mais longa que larga, 24$26 \mu \mathrm{m}$ compr., 20-21,5 $\mu \mathrm{m}$ larg., istmo 5,5-6,3 $\mu \mathrm{m}$ larg., contorno subquadrangular, constrição mediana profunda, seno mediano linear, apertado, aberto nos ângulos; semicélula elíptica, margens laterais amplamente côncavas, levemente onduladas; margem superior aproximadamente reta; parede celular com 1-2 séries contínuas de grânulos intramarginais, 1 círculo de grânulos logo acima do istmo; cloroplastídio axial.

Material examinado: BRASIL. BAHIA: Camaçari, APA Lagoas de Guarajuba, 12-I-2007, I.B. Oliveira \& I.S. Oliveira s.n. (HUEFS125503, HUEFS125504, HUEFS125506, HUEFS125508, HUEFS125509); 

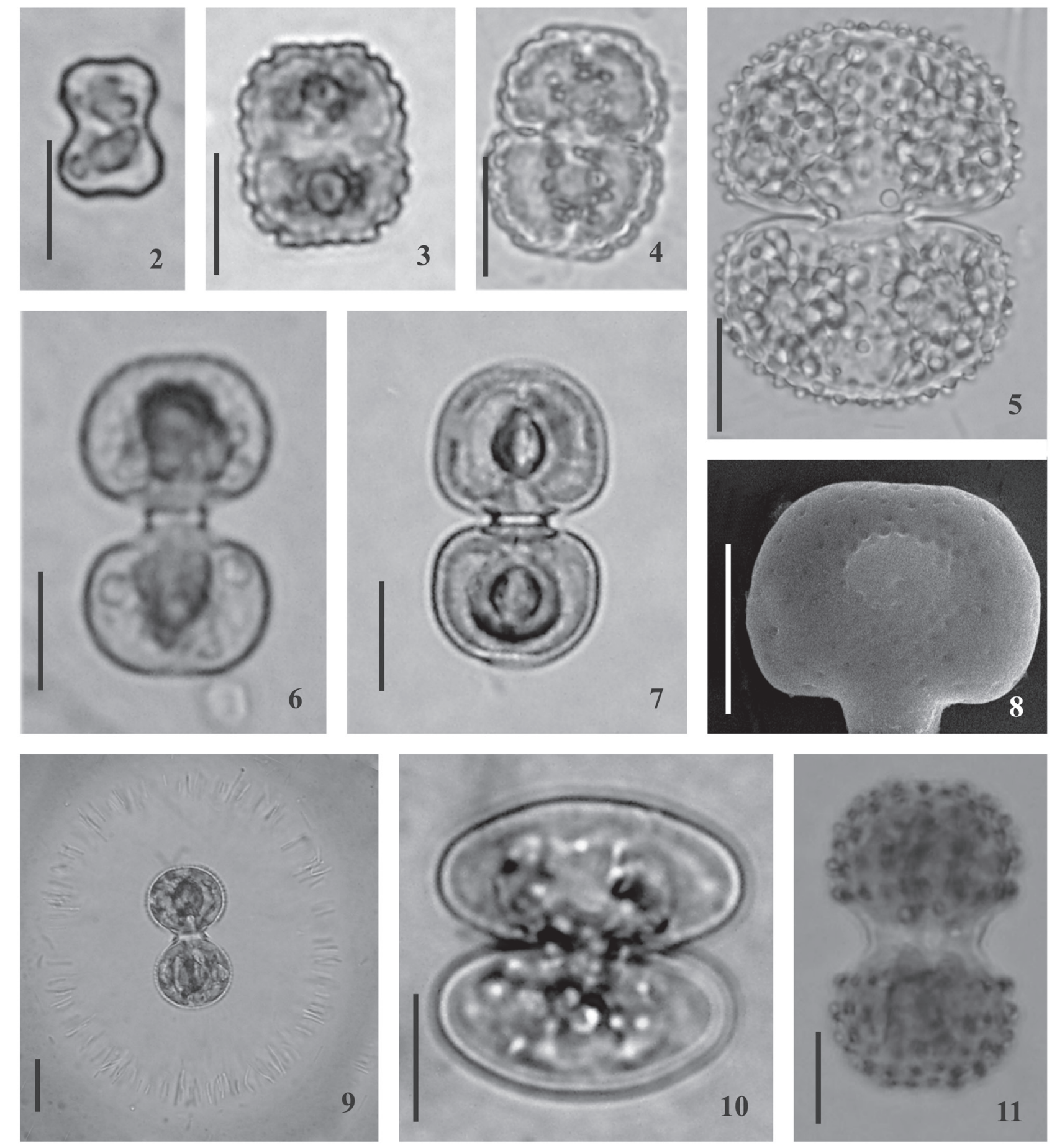

Figuras 2-11. Espécies de Cosmarium das APAs Lagoas de Guarajuba e Rio Capivara, Bahia, Brasil. 2. Cosmarium arctoum var. minor. 3-4. C. blyttii var. blyttii. 5. C. conspersum var. conspersum f. conspersum. 6-8. C. contractum var. contractum f. contractum. 9. C. contractum var. rotundatum f. rotundatum. 10. C. depressum var. elevatum. 11. C. excavatum var. excavatum. Figuras 3-4, 6-8 (Barras $=$ $10 \mu \mathrm{m})$; Figuras 2, 5, 9-11 (Barras $=20 \mu \mathrm{m})$.

Figures 2-11. Species of Cosmarium from APA Lagoas de Guarajuba and APA Rio Capivara, Bahia, Brasil. 2. Cosmarium arctoum var. minor. 3-4. C. blyttii var. blyttii. 5. C. conspersum var. conspersum f. conspersum. 6-8. C. contractum var. contractum f. contractum. 9. C. contractum var. rotundatum f. rotundatum. 10. C. depressum var. elevatum. 11. C. excavatum var. excavatum. Figures 3-4, 6-8 (Barr $=10 \mu \mathrm{m})$; Figures 2, 5, 9-11 $($ Barr $=20 \mu \mathrm{m})$. 
9-III-2007, I.B. Oliveira et al. s.n. (HUEFS125523, HUEFS125532, HUEFS125534, HUEFS125538); APA Rio Capivara, 9-III-2007, I.B. Oliveira et al. s.n. (HUEFS125521, HUEFS125546, HUEFS125547, HUEFS125551, HUEFS125554, HUEFS125560).

Distribuição geográfica no Brasil: Bahia (Martins \& Bicudo 1987), Minas Gerais e São Paulo (Bicudo 1969).

Morfologicamente $C$. furcatospermum se parece com C. sphalerostichum Nordst., do qual difere, sobretudo, por apresentar ápices ondulados, área central da semicélula lisa e vista apical relativamente mais estreita.

Cosmarium galeritum Nordst. var. subtumidum Borge, Ark. Bot. 1: 95, pl. 3, fig. 14. 1903.

Figura 16

Célula 1,1-1,3 vezes mais longa que larga, 65$71 \mu \mathrm{m}$ compr., 56-60 $\mu \mathrm{m}$ larg., istmo 23-28 $\mu \mathrm{m}$ larg., contorno subcircular, constrição mediana profunda, seno mediano fechado, linear; semicélula semicircular, margens laterais côncavas, margem apical arredondada; parede celular hialina, pontuada; cloroplastídio axial; pirenóide não observado.

Material examinado: BRASIL. BAHIA: Camaçari, APA Lagoas de Guarajuba, 12-I-2007, I.B. Oliveira \& I.S. Oliveira s.n. (HUEFS125510); 8-VI-2007, I.B. Oliveira et al. s.n. (HUEFS125579); 20-VII-2007, I.B. Oliveira et al. s.n. (HUEFS125597); 25-VIII2007, I.B. Oliveira et al. s.n. (HUEFS125617); APA Rio Capivara, 09-III-2007, I.B. Oliveira et al. s.n. (HUEFS125521, HUEFS125549); 20-VII-2007, I.B. Oliveira et al. s.n. (HUEFS125586).

Distribuição geográfica no Brasil: Mato Grosso (Borge 1903), Paraná (Felisberto \& Rodrigues 2008), Rio Grande do Sul (Sophia et al. 2005, Franceschini 1992, Bicudo \& Ungaretii 1986).

A var. subtumidum Borge difere da típica da espécie por apresentar a célula relativamente menos intumescida em vista vertical e pouco mais larga em vista lateral. Bicudo \& Ungaretti (1986) comentaram que a presença de formas intermediárias entre a variedade típica da espécie e a var. subtumidum compromete muito a separação de ambas. Sophia et al. (2005) descreveram espécimes 1,8-2 vezes mais longas que largas, diferindo neste aspecto, dos espécimes examinados.

Cosmarium gemminatum Lundell var. scottii Först., Amazoniana 2(1-2): 50, pl. 18, fig. 7-8. 1969. Figura 17
Célula tão longa quanto larga, 24-28 $\mu \mathrm{m}$ compr., 23-27 $\mu \mathrm{m}$ larg., istmo 8-10 $\mu \mathrm{m}$ larg., contorno subquadrangular, constrição mediana profunda, seno mediano fechado na região proximal, dilatado na porção distal; semicélula oblonga, margens basais retas a levemente aconcavadas, margens laterais côncavas, margem apical retusa; parede celular hialina, 7-8 fileiras de verrugas dispostas verticalmente, 1 verruga maior, supraistmial; cloroplastídios 2, parietais, preenchendo todo o espaço celular; pirenóides 2 .

Material examinado: BRASIL. BAHIA: Camaçari, APA Lagoas de Guarajuba, 12-I-2007, I.B. Oliveira \& I.S. Oliveira s.n. (HUEFS125507, HUEFS125508, HUEFS125510); APA Rio Capivara, 9-III-2007, I.B. Oliveira et al. s.n. (HUEFS125521, HUEFS125539, HUEFS125546).

Distribuição geográfica no Brasil: Amazonas (Förster 1969).

O presente táxon difere da variedade típica da espécie por apresentar, segundo Förster (1969), medidas celulares maiores, células tão longas quanto largas e verrugas supraistmiais relativamente maiores. Quanto à morfologia, C. gemminatum var. scottii lembra $C$. subtriordinatum West \& G.S.West. var. acervatum Först., diferindo por apresentar o seno mediano linear, apertado, a margem apical arredondada e grânulos todos iguais.

Cosmarium granatum Bréb. ex Ralfs var. concavum Lagerh., An. Univ. Centr. Equador [Quito]: 282. 1890.

Figura 18

Célula 1,45-1,55 vezes mais longa que larga, 31-35 $\mu \mathrm{m}$ compr., 21,5-22,5 $\mu \mathrm{m}$ larg., istmo 6,5$7 \mu \mathrm{m}$ larg., contorno ovalado, constrição mediana profunda, seno mediano linear, estreitamente aberto em toda sua extensão; semicélula piramidal-truncada, margens laterais aconcavadas no meio, convergentes em direção para o ápice, margem apical retusa; parede celular hialina, delicadamente pontuada; cloroplastídio acompanhando o formato da célula; pirenóides não observados.

Material examinado: BRASIL. BAHIA: Camaçari, APA Lagoas de Guarajuba, 12-I-2007, I.B. Oliveira \& I.S. Oliveira s.n. (HUEFS125503, HUEFS125504, HUEFS125507, HUEFS125508); APA Rio Capivara, 9-III-2007, I.B. Oliveira et al. s.n. (HUEFS125521). Distribuição geográfica no Brasil: Rio de Janeiro (Lima 1982), Rio Grande do Sul (Sophia et al. 2005). A var. concavum Lagerh. difere da variedade 
típica da espécie por apresentar as margens laterais fortemente aconcavadas na porção média da semicélula. Cosmarium granatum var. concavum difere dos espécimes examinados por Sophia et al. (2005) em relação ao tamanho da célula, as autores apresentam $(40-44 \times 32-36 \mu \mathrm{m}$, istmo $8-10 \mu \mathrm{m})$, maior do que os encontrado nas populações da Bahia. As populações analisadas neste estudo estão de acordo com as descrições, medidas e ilustrações apresentadas por Lima (1982) e Prescott et al. (1981).

Cosmarium impressulum Elfvin var. impressulum, Acta Soc. Fauna Flora Fenn. 2(2): 13, fig. 9. 1881. Figura 19

Célula 1,5-1,7 vezes mais longa que larga, 22$34 \mu \mathrm{m}$ compr., 14-20 $\mu \mathrm{m}$ larg., istmo 5-7 $\mu \mathrm{m}$ larg., contorno ovalado, constrição mediana profunda, seno estreitamente linear, extremidade levemente dilatada, semicélulas semi-elípticas, margem apical retusa, levemente côncava no meio, margens laterais 6-onduladas; parede celular hialina, lisa; cloroplastos 2 por semicélula; pirenóides não observados.

Material examinado: BRASIL. BAHIA: Camaçari, APA Lagoas de Guarajuba, 12-I-2007, I.B. Oliveira \& I.S. Oliveira s.n. (HUEFS125507); 9-III-2007, I.B. Oliveira et al. s.n. (HUEFS125523, HUEFS125533); 8-VI-2007, I.B. Oliveira et al. s.n. (HUEFS125581); 20-VII-2007, I.B. Oliveira et al. s.n.(HUEFS125593); APA Rio Capivara, 12-I-2007, I.B. Oliveira \& I.S. Oliveira s.n. (HUEFS125512); 8-VI-2007, I.B. Oliveira et al. s.n. (HUEFS125570); 25-VIII-2007, I.B. Oliveira et al. s.n. (HUEFS125605).

Distribuição geográfica no Brasil: Mato Grosso (De-Lamonica-Freire 1985), Pará (Grönblad 1945), Paraná (Felisberto \& Rodrigues 2005, Silva \& Cecy 2004), São Paulo (Araújo \& Bicudo 2006).

Quanto à morfologia, C. impressulum var. impressulum pode ser confundido com $C$. undulatum Corda ex Ralfs. Contudo, distingue por apresentar medidas celulares maiores (44-64 $\mu \mathrm{m}$ compr., 30$52 \mu \mathrm{m}$ larg.), semicélulas semi-elípticas e possuir 10 a 12 ondulações nas margens laterais. West \& West (1908) comentaram a existência de formas de transição entre $C$. impressulum var. impressulum $\mathrm{e}$ C. meneghinii Bréb., porém, exemplares típicos da espécie em questão podem ser de fácil identificação a partir da observação, principalmente, da forma das semicélulas. Segundo Araújo \& Bicudo (2006), quando as características são analisadas em conjunto faz com que não exista maior razão para situar $C$. impressulum var. impressulum como uma variedade dentro de C. meneghinii, pois as oito ondulações proeminentes situadas na margem da célula e o espaço entre as duas ondulações apicais, que dá a aparência de divisão da semicélula em lobos, torna relativamente fácil a identificação de $C$. impressulum var. impressulum.

Cosmarium lagoense Nordst. var. amoebum Först., Hydrobiologia 23(3-4): 394, pl. 24, fig. 10-13, pl. 45, fig. 13, pl. 46, fig. 5-6. 1964.

Figuras 20-21

Célula 1,1-1,3 vezes mais larga que longa, 41,5-43 $\mu \mathrm{m}$ compr., 46,5-48 $\mu \mathrm{m}$ larg., istmo 10$11 \mu \mathrm{m}$ larg., contorno subquadrangular, constrição mediana profunda, seno mediano estreito, semicélula reniforme, margens laterais côncavas, ornadas com espinhos curtos, margem apical amplamente arredondada, quase reta no meio, ornada com 1 série de espinhos curtos, fortes; parede celular de hialina a acastanhada, região mediana e laterais com 3-4 séries de espinhos curtos; 1 inflação mediana em cada lado da célula; cloroplastídio parietal; pirenóide não observado.

Material examinado: BRASIL. BAHIA: Camaçari, APA Lagoas de Guarajuba, 12-I-2007, I.B. Oliveira \& I.S. Oliveira s.n. (HUEFS125503, HUEFS125504, HUEFS125507, HUEFS125508, HUEFS125509); 9-III-2007, I.B. Oliveira et al. s.n. (HUEFS125523, HUEFS125532, HUEFS125533, HUEFS125543); 8-VI-2007, I.B. Oliveira et al. s.n. (HUEFS125579); 25-VIII-2007, I.B. Oliveira et al. s.n. (HUEFS125615, HUEFS125617); APA Rio Capivara, 12-I-2007, I.B. Oliveira \& I.S. Oliveira s.n. (HUEFS125512, HUEFS125519, HUEFS125520); 9-III-2007, I.B. Oliveira et al. s.n. (HUEFS125521, HUEFS125549, HUEFS125551); 25-VIII-2007, I.B. Oliveira et al. s.n. (HUEFS125605, HUEFS125608).

Distribuição geográfica no Brasil: Amazonas (Förster 1969), Goiás (Förster 1964, Felisberto \& Rodrigues 2004), Pará (Suárez-Mera 1995).

Förster (1964) propôs a var. amoebum a partir de material coletado em Conceição, estado de Goiás e a diferiu da variedade tipo da espécie por apresentar espinhos marginais aculeados, laterais e a face central da semicélula ornamentada com verrugas poligonais ou vermiformes.

Cosmarium margaritatum (Lundell) Roy \& Bisset var. margaritatum f. margaritatum, Journ. Bot. 24: 194. 1885 三 Cosmarium latum Bréb. var. margaritatum Lundell, Nova Acta R. Soc. Scient. 

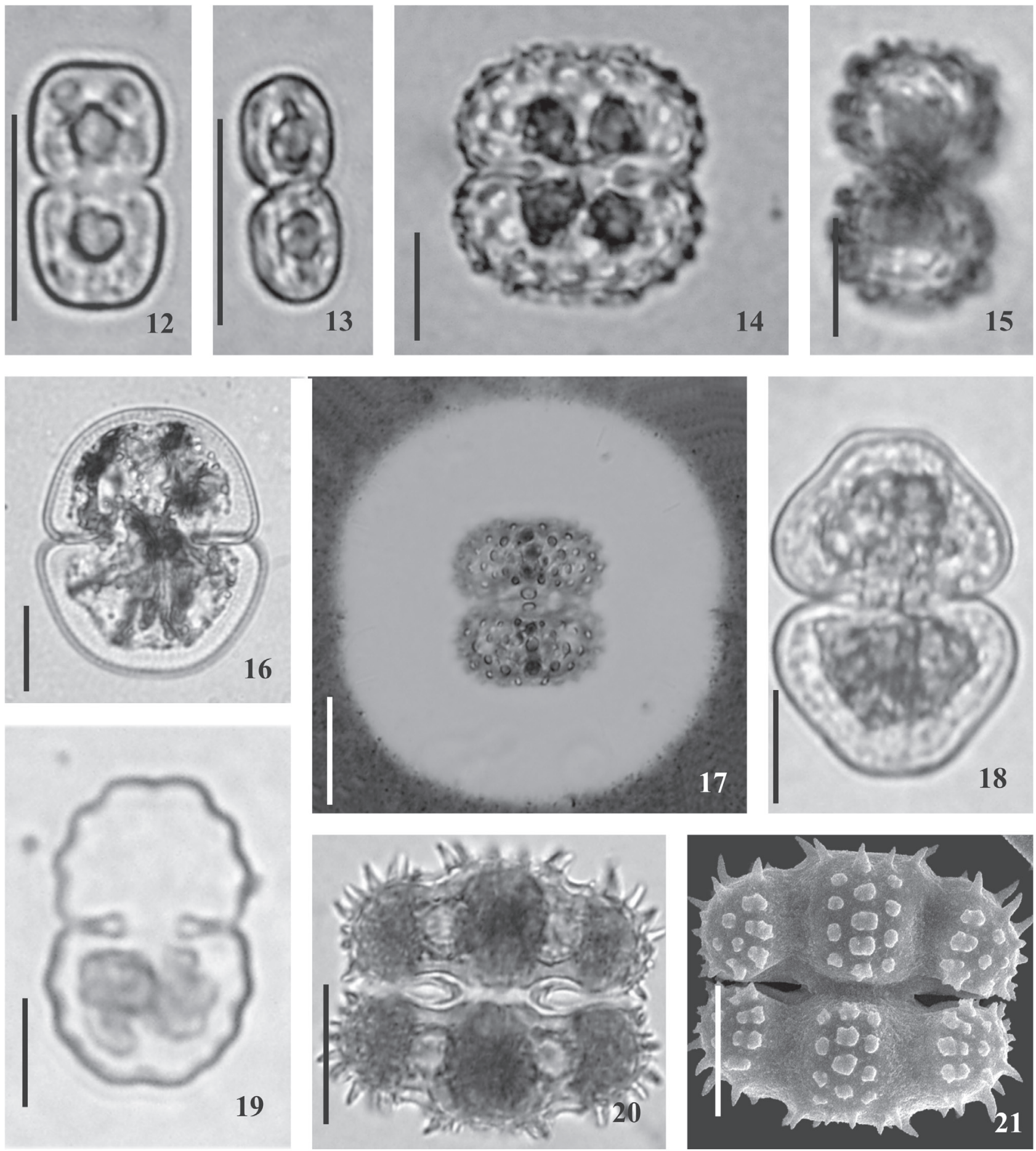

Figuras 12-21. Espécies de Cosmarium das APAs Lagoas de Guarajuba e Rio Capivara, Bahia, Brasil. 12-13. Cosmarium exiguum var. exiguum f. incrassatum. 14-15. C. furcatospermum. 16. C. galeritum var. subtumidum. 17. C. gemminatum var. scottii. 18. C. granatum var. concavum. 19. C. impressulum var. impressulum. 20-21. C. lagoense var. amoebum. Figuras 14-15, 17-19 (Barras =10 $\mu \mathrm{m})$; Figuras 12-13, 16, 20-21 $($ Barras $=20 \mu \mathrm{m})$.

Figures 12-21. Species of Cosmarium from APA Lagoas de Guarajuba and APA Rio Capivara, Bahia, Brasil. 12-13. Cosmarium exiguum var. exiguum f. incrassatum. 14-15. C. furcatospermum. 16. C. galeritum var. subtumidum. 17. C. gemminatum var. scottii. 18. C. granatum var. concavum. 19. C. impressulum var. impressulum. 20-21. C. lagoense var. amoebum. Figures 14-15, 17-19 (Barr=10 $\mu$ ); Figures 12-13, 16, 20-21 (Barr $=20 \mu \mathrm{m})$. 
Upsal., sér. 3, 8(2): 26. 1871.

Figuras 22-24

Célula 1,1-1,2 vezes mais longa que larga, 68-72 $\mu \mathrm{m}$ compr., 58-65 $\mu \mathrm{m}$ larg., istmo 20$25 \mu \mathrm{m}$ larg., contorno subquadrático, constrição mediana profunda, seno mediano linear, fechado em quase toda sua extensão; semicélula oblongoelíptica, margens apical e laterais crenuladas, apical arredondada, laterais convexas, às vezes com 1 leve retusidade no meio; parede celular hialina a levemente acastanhada, densamente granulada, grânulos sólidos dispostos obliquamente, pontuações entre os grânulos; cloroplastídio axial; pirenóides 2 em cada semicélula.

Material examinado: BRASIL. BAHIA: Camaçari, APA Lagoas de Guarajuba, 12-I-2007, I.B. Oliveira \& I.S. Oliveira s.n. (HUEFS125509, HUEFS125510); 9-III-2007, I.B. Oliveira et al. s.n. (HUEFS125523, HUEFS125533, HUEFS125537, HUEFS125544); 8-VI-2007, I.B. Oliveira et al. s.n. (HUEFS125577, HUEFS125581); 20-VII-2007, I.B. Oliveira et al. s.n. (HUEFS125597); 25-VIII-2007, I.B. Oliveira et al. s.n. (HUEFS125617, HUEFS125620); APA Rio Capivara 09-III-2007, I.B. Oliveira et al. s.n. (HUEFS125545, HUEFS125548, HUEFS125551, HUEFS125571); 20-VII-2007, I.B. Oliveira et al. s.n. (HUEFS125583, HUEFS125586); 25-VIII-2007, I.B. Oliveira et al. s.n. (HUEFS125607, HUEFS125608). Distribuição geográfica no Brasil: Amazônia (Lopes \& Bicudo 2002, Förster 1963), São Paulo (Agujaro 1990).

Cosmarium margaritatum lembra, morfologicamente, C. quadrum P.Lundell, porém, difere por apresentar semicélulas transversalmente sub-retangulares e margem apical mais ampla. As medidas das populações obtidas durante este estudo são menores do que as citadas por Lopes \& Bicudo (2002), porém, maiores do que as da f. minor (Boldt) West \& G.S.West citada pela mesma autora. Agujaro (1990) e Prescott et al. (1981), sugeriram a união da f. minor e da típica da espécie em um único táxon, já que os limites métricos máximos da f. minor e o mínimo da forma típica praticamente se sobrepõem. Lopes \& Bicudo (2002) examinaram populações cujos limites métricos foram distintos, levando à identificação das duas formas taxonômicas, f. minor e forma típica.

Cosmarium moerlianum Lütkem. var. brasiliense Borge, Ark. Bot. 15(13): 36, pl. 3, fig. 13. 1918. Figura 25
Célula 1,2-1,3 vezes mais longa que larga, 22-30 $\mu \mathrm{m}$ compr., 16-24,5 $\mu \mathrm{m}$ larg., istmo 5,5-8 $\mu \mathrm{m}$ larg., contorno amplamente elíptico, constrição mediana profunda, seno mediano fechado, linear, levemente aberto a partir do meio para a parte distal; semicélula aproximadamente trapeziforme, margens laterais paralelas entre si, 2-3-onduladas, depois convergentes para o ápice, margem apical amplamente convexa; parede celular hialina, 2 grânulos na porção média das margens laterais, 2 grânulos próximo ao ápice; 2 cloroplastídios por semicélula; pirenóides vários, pequenos, esparsos.

Material examinado: BRASIL. BAHIA: Camaçari, APA Rio Capivara, 12-I-2007, I.B. Oliveira \& I.S. Oliveira s.n. (HUEFS125518); 9-III-2007, I.B. Oliveira et al. s.n. (HUEFS125547, HUEFS125549); 8-VI-2007, I.B. Oliveira et al. s.n. (HUEFS125570, HUEFS125571).

Distribuição geográfica no Brasil: Mato Grosso (De-Lamonica-Freire 1985), Paraná (Felisberto \& Rodrigues 2005), São Paulo (Borge 1918).

A var. brasiliense foi proposta por Borge (1918) a partir de material coletado em Pirassununga, estado de São Paulo. Difere da variedade típica da espécie por não apresentar dois grânulos intramarginais de cada lado da semicélula, nem a inflação central ornamentada com dois grânulos na face da semicélula. Os exemplares ora identificados provenientes das duas APAs do litoral norte da Bahia estão de acordo com as descrições e ilustrações apresentadas por, Prescott et al. (1981) para exemplares dos Estados Unidos da América, Förster (1982) para exemplares da Europa.

\section{Cosmarium monomazum Lundell var. dimazum}

Krieg. f. brasiliense Först., Hydrobiologia 23(34): 396, pl. 22, fig. 24, pl. 47, fig. 18. 1964.

Figuras 26-28

Célula tão longa quanto larga, 31,5-35 $\mu \mathrm{m}$ compr., 31,5-35 $\mu \mathrm{m}$ larg., 12,5-14 $\mu \mathrm{m}$ espess., istmo 7,5-8,5 $\mu \mathrm{m}$ larg., contorno subcircular, envolvida por bainha abundante, nítida, constrição mediana profunda, seno mediano linear, fechado; semicélula semicircular em vista frontal, 2 pequenas projeções na região mediana, margens granulosas, laterais convexas, apical levemente truncada; parede celular com 2 fileiras de grânulos dispostos paralelamente entre si no limite da porção espessada da semicélula, demais regiões lisas; cloroplastídios 2, axiais, pirenóide 1, central em cada plastídio.

Material examinado: BRASIL. BAHIA: Camaça- 
ri, APA Lagoas de Guarajuba, 9-III-2007, I.B. Oliveira et al. s.n. (HUEFS125523, HUEFS125532, HUEFS125533, HUEFS125543); 20-VII-2007, I.B. Oliveira et al. s.n. (HUEFS125593, HUEFS125597); 25-VIII-2007, I.B. Oliveira et al. s.n. (HUEFS125608); APA Rio Capivara 9-III-2007, I.B. Oliveira et al. s.n. (HUEFS125548); 8-VI-2007, I.B. Oliveira et al. s.n.(HUEFS125566, HUEFS125570, HUEFS125571, HUEFS125582); 25-VIII-2007, I.B. Oliveira et al. s.n. (HUEFS125605, HUEFS125607, HUEFS125608).

Distribuição geográfica no Brasil: Goiás (Förster 1964).

Förster (1964) propôs a f. brasiliense com base em material coletado em Conceição, estado de Goiás. Segundo o referido autor, a f. brasiliense difere da forma típica da var. dimazum Krieg. por apresentar medidas celulares inferiores e parede celular hialina e lisa. É uma forma taxonômica de identificação relativamente fácil, pois apresenta características típicas como o contorno celular subcircular e a ornamentação com dois grânulos na face da semicélula, logo acima do istmo. Morfologicamente C. monomazum var. dimazum f. brasiliense Först. lembra $C$. cuneatum Joshua, contudo, este último difere por apresentar três fileiras de pequenos espinhos na vista apical e face da semicélula ornamentada com quatro grânulos.

Cosmarium obsoletum (Hantzsch) Reinsch var. obsoletum, Acta Soc. Senckenberg 6: 142, pl. 22D1, fig. 1-4. $1867 \equiv$ Arthrodesmus obsoletus Hantzsch, in Rabenhorst, Algen Europa's. $n^{\circ}$ 1407. 1862.

Figura 29

Célula 1,1-1,2 vezes mais longa que larga, 47,552,5 $\mu \mathrm{m}$ compr., 42,5-45 $\mu \mathrm{m}$ larg., istmo 17,5-20 $\mu \mathrm{m}$ larg., contorno subcircular, constrição mediana profunda, seno mediano fechado, retilíneo, levemente aberto nos ângulos, semicélula elíptica, margens laterais lisas, côncavas, margem apical retusa a amplamente arredondada; parede celular hialina, finamente pontuada; cloroplastídio axial; pirenóides 2.

Material examinado: BRASIL. BAHIA: Camaçari, APA Lagoas de Guarajuba, 9-III-2007, I.B. Oliveira et al. s.n. (HUEFS125534); 8-VI-2007, I.B. Oliveira et al. s.n. (HUEFS125577); 20-VII-2007, I.B. Oliveira et al. s.n. (HUEFS125598); APA Rio Capivara, 12I-2007, I.B. Oliveira et al. s.n. (HUEFS125520); 9-III-2007, I.B. Oliveira et al. s.n. (HUEFS125549,
HUEFS125561), 20-VII-2007, I.B. Oliveira et al. s.n. (HUEFS125586).

Distribuição geográfica no Brasil: Amazônia (Förster 1969), Goiás (Felisberto \& Rodrigues 2004), São Paulo (Araújo \& Bicudo 2006, Marinho \& Sophia 1997).

Cosmarium obsoletum var. obsoletum lembra bastante $C$. ralfsii Bréb. var. ralfsii, do qual difere unicamente por apresentar medidas celulares menores. Os espécimes presentemente examinados ainda estão de acordo com as descrições, medidas e ilustrações apresentadas por Ling \& Tayler (1985) para exemplares da Austrália, Bernard (1909) para exemplares da França e por Croasdale \& Flint (1988) para exemplares da Nova Zelândia.

Cosmarium ocellatum Eichler \& Gutw. var. incrassatum West \& G.S.West, Jour. Roy. Microsc. Soc. 33: 485, pl. 6, fig. 12. 1897. Figuras 30-31

Célula 1,5-1,6 vezes mais longa que larga, 32-38 $\mu \mathrm{m}$ compr., 20-28 $\mu \mathrm{m}$ larg., istmo 6-8 $\mu \mathrm{m}$ larg., contorno sub-rombóide, constricção mediana profunda, seno mediano linear, fechado; semicélula piramidal-truncada, margens laterais e apical lisas, laterais retas a levemente convexas, convergindo para o ápice, ápice truncado; parede celular hialina a acastanhada, finamente pontuada, face da semicélula decorada com 1 grande concavidade, localizada a meia distância entre a margem lateral e o centro da semicélula; cloroplastídio axial, preenchendo todo o espaço celular; pirenóides 4-5, pequenos.

Material examinado: BRASIL. BAHIA: Camaçari, APA Lagoas de Guarajuba, 9-III-2007, I.B. Oliveira et al. s.n. (HUEFS125534); 8-VI-2007, I.B. Oliveira et al. s.n. (HUEFS125577); 20-VII-2007, I.B. Oliveira et al. s.n. (HUEFS125598); APA Rio Capivara, 12I-2007, I.B. Oliveira et al. s.n. (HUEFS125520); 9-III-2007, I.B. Oliveira et al. s.n. (HUEFS125549, HUEFS125561); 20-VII-2007, I.B. Oliveira et al. s.n. (HUEFS125586).

Distribuição geográfica no Brasil: Pará (Grönblad 1945).

A var. incrassatum West \& G.S. West difere da variedade típica da espécie por apresentar medidas celulares menores, bem como possuir a relação entre o comprimento e a largura celular superiores. Morfologicamente, é semelhante a $C$. granatum Bréb. ex Ralfs var. concavum Lagerh., da qual difere por apresentar a face da semicélula com uma grande concavidade localizada a meia distância entre a margem lateral e o centro da semicélula. 

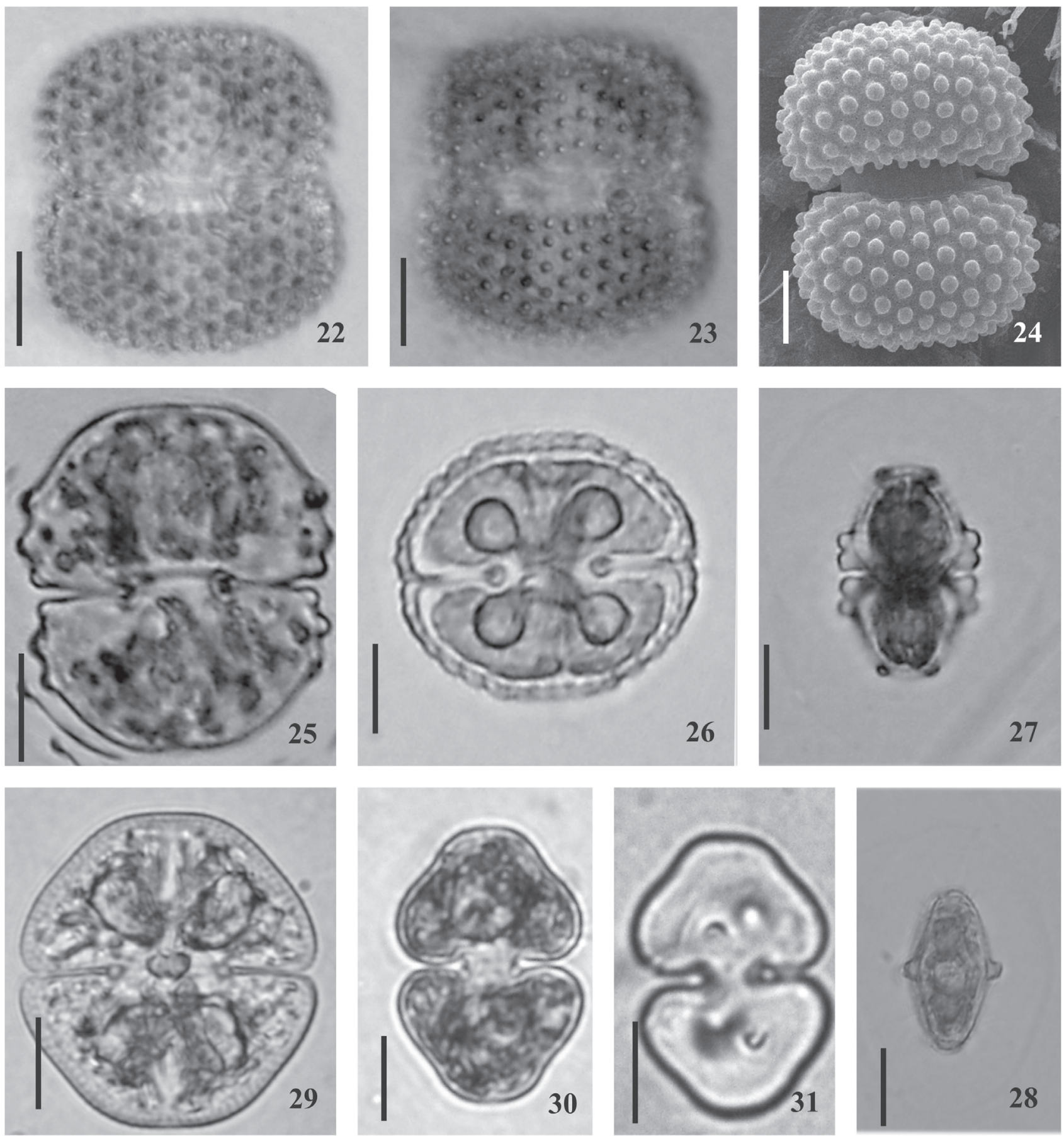

Figuras 22-31. Espécies de Cosmarium das APAs Lagoas de Guarajuba e Rio Capivara, Bahia, Brasil. 22-24. Cosmarium margaritatum var. margaritatum f. margaritatum. 24. Microscopia eletrônica de varredura 25. C. moerlianum var. brasiliense. 26-28. C. monomazum var. dimazum f. brasiliense. 29. C. obsoletum var. obsoletum. 30-31. C. ocellatum var. incrassatum. Figuras 25-28, 30-31 (Barras = $10 \mu \mathrm{m})$; Figuras 22-24, $29($ Barras $=20 \mu \mathrm{m})$.

Figures 22-31. Species of Cosmarium from APA Lagoas de Guarajuba and APA Rio Capivara, Bahia, Brasil. 22-24. Cosmarium margaritatum var. margaritatum f. margaritatum. 24. Scanning electron microscopy. 25. C. moerlianum var. brasiliense. 26-28. C. monomazum var. dimazum f. brasiliense. 29. C. obsoletum var. obsoletum. 30-31. C. ocellatum var. incrassatum. Figures 25-28, 30-31 $($ Barr $=10 \mu \mathrm{m})$; Figures 22-24, $29($ Barr $=20 \mu \mathrm{m})$. 
Cosmarium ornatum Ralfs var. ornatum f. ornatum, Brit. Desmidieae: 104, pl. 17, fig. 7. 1848. Figuras 32-34

Célula quase tão longa quanto larga, 32-40 $\mu \mathrm{m}$ compr., 36-42,5 $\mu \mathrm{m}$ larg., ca. 22,5 $\mu \mathrm{m}$ espess., istmo 7,5-11 $\mu \mathrm{m}$ larg., contorno subquadrangular, constrição mediana profunda, seno mediano estreito, aberto próximo do istmo, depois fechado até a extremidade; semicélula levemente reniforme; margens laterais côncavas, ornadas com verrugas, margem apical amplamente arredondada, quase reta, levemente pronunciada, 1 série de verrugas; parede celular hialina, 1 intumescência proeminente na região mediana, 1 círculo de grânulos arredondados, arranjados em curtas séries transversais ou aleatórias; cloroplastídios 2, axiais por semicélula; pirenóide 1 em cada plastídio.

Material examinado: BRASIL. BAHIA: Camaçari, APA Lagoas de Guarajuba, 12-I-2007, I.B. Oliveira \& I.B. Oliveira s.n. (HUEFS125504); 9-III-2007, I.B. Oliveira et al. s.n. (HUEFS125542); 8-VI-2007, I.B. Oliveira et al. s.n. (HUEFS125579); 20-VII2007, I.B. Oliveira et al. s.n. (HUEFS125596); $25-$ VIII-2007, I.B. Oliveira et al. s.n. (HUEFS125620); APA Rio Capivara, 12-I-2007, I.B. Oliveira et al. s.n. (HUEFS125519); 9-III-2007, I.B. Oliveira et al. s.n. (HUEFS125545, HUEFS125550, HUEFS125560); 20-VII-2007, I.B. Oliveira et al. s.n. (HUEFS125586); 25-VIII-2007, I.B. Oliveira et al. s.n. (HUEFS125604, HUEFS125605).

Distribuição geográfica no Brasil: Rio Grande do Sul (Franceschini 1992, Bicudo \& Ungaretii 1986).

Cosmarium ornatum var. ornatum f. ornatum é uma espécie relativamente fácil de identificar por apresentar semicélulas levemente reniformes e ornamentação na intumescência central. Segundo West \& West (1908), esse táxon apresenta alguma variação morfológica, especialmente na forma dos grânulos da ornamentação da protuberância da face central da semicélula. Os referidos autores comentaram também as figuras originais de Ralfs (1848: pl. 16, fig. 17) definindo-as como não sendo boas, por representar muito mal os grânulos centrais, além de exagerar a proeminência dos ápices.

Cosmarium ornatum Ralfs var. pseudolagoense Först. \& Eckert, Hydrobiologia 23(3-4): 399, pl. 24, fig. 9, pl. 7, fig. 2. 1964.

Figuras 35-36

Célula tão longa quanto larga, 32-40 $\mu \mathrm{m}$ compr.,
36-42,5 $\mu \mathrm{m}$ larg., ca. $22,5 \mu \mathrm{m}$ espess., istmo 7,5-11 $\mu \mathrm{m}$ larg., contorno subquadrangular, constrição mediana profunda, seno mediano estreito, aberto próximo do istmo e fechado nas extremidades; semicélula transversalmente oblonga, margens laterais côncavas, ornadas com verrugas cuneiformes, margem apical amplamente arredondada, quase reta no meio, ornada com 1 série de verrugas cuneiformes; parede celular hialina a acastanhada, decorada na região mediana com 3-4 séries de verrugas cuneiformes; 1 anel de verrugas cuneiformes na região central; cloroplastídio e pirenóide não observados.

Material examinado: BRASIL. BAHIA: Camaçari, APA Lagoas de Guarajuba, 12-I-2007, I.B. Oliveira \& I.B. Oliveira s.n. (HUEFS125505); 9-III2007, I.B. Oliveira et al. s.n. (HUEFS125534, HUEFS125543); 8-VI-2007, I.B. Oliveira et al. s.n. (HUEFS125577); 20-VII-2007, I.B. Oliveira et al. s.n. (HUEFS12559); 25-VIII-2007, I.B. Oliveira et al. s.n. (HUEFS125617); APA Rio Capivara, 9-III-2007, I.B. Oliveira et al. s.n. (HUEFS125521, HUEFS125560, HUEFS125570); 25-VIII-2007, I.B. Oliveira et al. s.n. (HUEFS125605, HUEFS125606). Distribuição geográfica no Brasil: Amazonas (Thomasson 1971, Förster 1969), Bahia (Bicudo \& Martins 1989), Goiás (Förster 1964).

Förster (1964) propôs a var. pseudolagoense a partir de material coletado em Conceição, estado de Goiás e a diferiu da variedade típica da espécie por apresentar células tão longas quanto largas, semicélulas com as margens laterais côncavas e verrugas cuneiformes. Morfologicamente, é semelhante a $C$. comissulare Bréb. var. crassum Nordst. da qual difere por apresentar os espinhos das margens apical e lateral pontiagudos e o seno mediano estreito, aberto próximo do istmo e fechado nas extremidades.

Cosmarium orthostichum Lundell var. pumilum Lundell, Nova Acta R. Soc. Scient. Upsal. 3, 8(2): 25, pl. 2, fig. 101. 1871.

Figura 37

Célula tão larga quanto longa, 20-22 $\mu \mathrm{m}$ compr., 20-22 $\mu \mathrm{m}$ larg., istmo 6-8 $\mu \mathrm{m}$ larg., contorno subquadrangular, constrição mediana profunda, seno mediano estreito, linear; semicélula transversalmente oblonga, margens laterais côncavas, margem apical arredondada; parede celular hialina, 4-5 séries transversais de pequenas verrugas arranjadas em 7-8 fileiras verticais; cloroplastídio parietal, preenchendo todo o espaço celular; pirenóide não observado. 
Material examinado: BRASIL. BAHIA: Camaçari, APA Lagoas de Guarajuba, 12-I-2007, I.B. Oliveira \& I.B. Oliveira s.n. (HUEFS125503); 9-III2007, I.B. Oliveira et al. s.n. (HUEFS125523, HUEFS125539); 20-VII-2007, I.B. Oliveira et al. s.n. (HUEFS125598); 25-VIII-2007, I.B. Oliveira et al. s.n. (HUEFS125617); APA Rio Capivara, 12-I-2007, I.B. Oliveira e I.B. Oliveira s.n. (HUEFS125512); 9-III-2007, I.B. Oliveira et al. s.n. (HUEFS125561); 20-VII-2007, I.B. Oliveira et al. s.n. (HUEFS125583); 25-VIII-2007, I.B. Oliveira et al. s.n. (HUEFS125607).

Distribuição geográfica no Brasil: Mato Grosso (DeLamonica-Freire 1985), Pará (Förster 1969).

Esta variedade difere da típica da espécie por apresentar medidas celulares relativamente menores e disposição dos grânulos em oito séries horizontais e cinco verticais.

Cosmarium pachydermum Lundell var. pachydermum f. pachydermum, Nova Acta R. Soc. Scient. Upsal. 3, 8(2): 39, pl. 2, fig. 15. 1871. Figura 38

Célula ca. 1,3-1,4 vezes mais longa que larga, 94-112 $\mu \mathrm{m}$ compr., 73-86 $\mu \mathrm{m}$ larg., istmo 32-40 $\mu \mathrm{m}$ larg., contorno elíptico-arredondado, constrição mediana profunda, seno mediano retilíneo, fechado, aberto nos ângulos, semicélula elíptica, margens laterais lisas, côncavas, margem apical retusa, uma leve convexidade no meio; parede celular hialina, finamente pontuada; cloroplastídio axial, lobado; pirenóides 2, centrais.

Material examinado: BRASIL. BAHIA: Camaçari, APA Lagoas de Guarajuba, 8-VI-2007, I.B. Oliveira et al. s.n. (HUEFS125577); 20-VII-2007, I.B. Oliveira et al. s.n. (HUEFS125593); APA Rio Capivara 20-VII2007, I.B. Oliveira et al. s.n. (HUEFS125589); $25-$ VIII-2007, I.B. Oliveira et al. s.n. (HUEFS125604).

Distribuição geográfica no Brasil: Mato Grosso (DeLamonica-Freire 1985), Paraná (Bittencourt-Oliveira 2002), Rio Grande do Sul (Torgan et al. 2001), São Paulo (Araújo \& Bicudo 2006, Taniguchi et al. 2003).

Cosmarium pachydermum confunde-se, morfologicamente, com $C$. ralfsii Bréb. var. ralfsii e C. lundellii Delponte var. lundellii, contudo difere do primeiro por apresentar istmo mais estreito, semicélula triangular-arredondada e vários pirenóides distribuídos irregularmente no cloroplastídio; e do segundo, por apresentar semicélulas infladas, de contorno triangular-arredondado e vista apical ovalada, com uma leve inflação mediana.
Prescott et al. (1981) observaram espécimes com três pirenóides em uma semicélula e dois na outra. Em todo o material examinado, não foi vista essa variação, porém, foi observado sempre dois pirenóides em cada semicélula.

Cosmarium pseudoconnatum Nordst. var. pseudoconnatum, Vidensk. Meddr Naturh. Foren. Kjöbenhavn 21: 214, pl. 3, fig. 17. 1869.

Figuras 39-40

Célula 1,2-1,4 vezes mais longa que larga, 55,5-61,5 $\mu \mathrm{m}$ compr., 37,5-41,5 $\mu \mathrm{m}$ larg., istmo 32,5-36,5 $\mu \mathrm{m}$ larg., contorno ovalado-arredondado, constrição mediana rasa, seno mediano aberto; semicélula subsemicircular, margens apical e laterais arredondadas, lisas, ápice amplamente arredondado; parede celular hialina, pontuada, região do istmo lisa; cloroplastídio axial, 4-radiado; pirenóides 4, 1 para cada projeção do cloroplastídio.

Material examinado: BRASIL. BAHIA: Camaçari, APA Lagoas de Guarajuba, 12-I-2007, I.B. Oliveira \& I.B. Oliveira s.n. (HUEFS125505, HUEFS125508, HUEFS125509); 9-III-2007, I.B. Oliveira et al. s.n. (HUEFS125533, HUEFS125537); 8-VI-2007, I.B. Oliveira et al. s.n. (HUEFS125577); 20-VII2007, I.B. Oliveira et al. s.n. (HUEFS125598); 25VIII-2007, I.B. Oliveira et al. s.n. (HUEFS125601, HUEFS125604, HUEFS125615); APA Rio Capivara, 12-I-2007, I.B. Oliveira \& I.B. Oliveira s.n. (HUEFS125512, HUEFS125518); 9-III-2007, I.B. Oliveira et al. s.n. (HUEFS125523, HUEFS125547, HUEFS125550); 8-VI-2007, I.B. Oliveira et al. s.n. (HUEFS12574); 20-VII-2007, I.B. Oliveira et al. s.n. (HUEFS125583); 25-VIII-2007, I.B. Oliveira et al. s.n. (HUEFS125607, HUEFS125615).

Distribuição geográfica no Brasil: Amazonas (Melo \& Souza 2009), Bahia (Bicudo \& Martins 1989), Espírito Santo (Delazari-Barroso et al. 2007), Goiás (Felisberto \& Rodrigues 2004), Minas Gerais (Nordstedt 1869), Pará (Grönblad 1945), Paraná (Felisberto \& Rodrigues 2008, Silva \& Cecy 2004), Rio Grande do Sul (Bicudo \& Ungaretii 1986), Rio de Janeiro (Lima 1982), São Paulo (Araújo \& Bicudo 2006, Bicudo 1969).

Cosmarium pseudoconnatum var. pseudoconnatum foi descrito originalmente por Nordstedt (1869) a partir de material coletado no estado de Minas Gerais. Nesse trabalho, o autor mencionou as ilustrações, porém, estas só foram publicadas 18 anos mais tarde, em Nordstedt (1877). Morfologicamente, a presente espécie lembra $C$. 

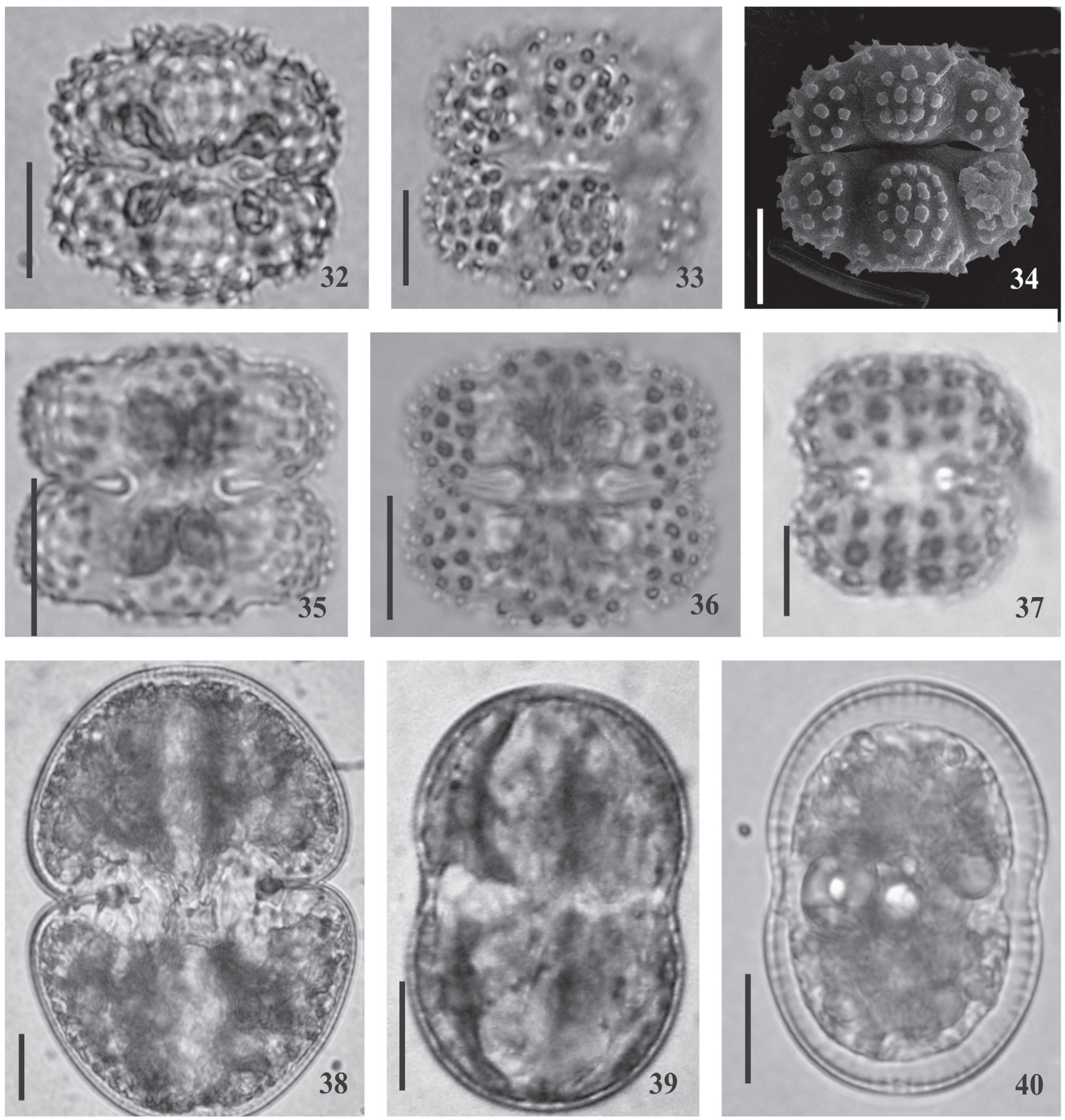

Figuras 32-40. Espécies de Cosmarium das APAs Lagoas de Guarajuba e Rio Capivara, Bahia, Brasil. 32-34. Cosmarium ornatum var. ornatum f. ornatum, 34. Micrografia eletrônica de varredura. 35-36. C. ornatum var. pseudolagoense. 37. C. orthostichum var. pumilum. 38. C. pachydermum var. pachydermum f. pachydermum. 39-40. C. pseudoconnatum var. pseudoconnatum. Figuras 32-33, 37 (Barras = $10 \mu \mathrm{m}) ; 34,35-36,38-40$ Figuras (Barras $=20 \mu \mathrm{m})$.

Figures 32-40. Species of Cosmarium from APA Lagoas de Guarajuba and APA Rio Capivara, Bahia, Brasil. 32-34. Cosmarium ornatum var. ornatum f. ornatum, 34. Scanning electron microscopy. 35-36. C. ornatum var. pseudolagoense. 37. C. orthostichum var. pumilum. 38. C. pachydermum var. pachydermum f. pachydermum. 39-40. C. pseudoconnatum var. pseudoconnatum. Figures $32-33,37$ (Barr $=$ $10 \mu \mathrm{m}) ; 34,35-36,38-40$ Figures $($ Barr $=20 \mu \mathrm{m})$. 
connatum Bréb. e Actinotaenium wollei (Grönblad) Teiling, tornando, às vezes, difícil a separação desses três materiais. C. pseudoconnatum. var. pseudoconnatum difere de C. connatum por possuir células relativamente menores, constrição mediana mais suave e pelas semicélulas proporcionalmente mais arredondadas (Bicudo, 1969); difere de $A$. wollei por apresentar dimensões celulares maiores e cloroplastídios em forma de carambola, isto é, com um eixo comum e margens lisas e expandidas contra a parede celular, que é característico do gênero.

Cosmarium pseudopyramidatum Lundell var. pseudopyramidatum f. pseudopyramidatum, Nova Acta R. Soc. Scient. Upsal. 3, 8(2): 41, pl. 2, fig. 18. 1871.

Figuras 41-42

Célula 1,6-1,7 vezes mais longa que larga, 6172,5 $\mu \mathrm{m}$ compr., 38,5-42,5 $\mu \mathrm{m}$ larg., istmo 12,5-15 $\mu \mathrm{m}$ larg., contorno ovalado, profundamente constrita na parte mediana, seno mediano linear, estreito, dilatado no ápice; semicélula piramidal-truncada, margens laterais levemente convexas a quase retas, ápice amplamente truncado a subtruncado; parede celular hialina, finamente pontuada; cloroplastídio axial; pirenóide 1 .

Material examinado: BRASIL. BAHIA: Camaçari, APA Lagoas de Guarajuba, 12-I-2007, I.B. Oliveira \& I.B. Oliveira s.n. (HUEFS125505, HUEFS125508, HUEFS125509); 9-III-2007, I.B. Oliveira et al. s.n. (HUEFS125523, HUEFS125543, HUEFS125554); 20-VII-2007, I.B. Oliveira et al. s.n.(HUEFS125593); APA Rio Capivara, 12-I-2007, I.B. Oliveira \& I.B. Oliveira s.n. (HUEFS125515); 9-III-2007, I.B. Oliveira et al. s.n. (HUEFS125550, HUEFS12551, HUEFS125566); 20-VII-2007, I.B. Oliveira et al. s.n. (HUEFS125584); 25-VIII-2007, I.B. Oliveira et al. s.n. (HUEFS125603, HUEFS125605).

Distribuição geográfica no Brasil: Amazonas (Melo \& Souza 2009), Bahia (Bicudo \& Martins 1989), Mato Grosso (Borge 1903), Paraná (Cetto et al. 2004), Rio Grande do Sul (Sophia et al. 2005, Borge 1903), Rio de Janeiro (Lima 1982).

Cosmarium pseudopyramidatum var. pseudopyramidatum f. pseudopyramidatum lembra C. pyramidatum Bréb. ex Ralfs var. pyramidatum $\mathrm{f}$. pyramidatum, do qual difere por possuir células de maior tamanho, margens laterais levemente convexas a quase retas e um pirenóide único por célula. Borge (1903) referiu à ocorrência da espécie nos estado do Rio Grande do Sul, Mato Grosso e no Paraguai, no entanto, não forneceu descrição, medidas nem ilustração do material que identificou. Assim sendo, não foi possível comparar com o material analisado durante esse estudo.

Cosmarium pseudopyramidatum Lundell var. borgei Krieg. \& Gerloff, Gatt. Cosmarium 2: 126, pl. 26, fig. 4a-c. 1965.

Figuras 43-44

Célula ca. 1,6 vezes mais longa que larga, 6574,5 $\mu \mathrm{m}$ compr., 40-45 $\mu \mathrm{m}$ larg., istmo 15-17 $\mu \mathrm{m}$ larg., contorno ovalado, profundamente constrita na parte mediana, seno mediano linear, estreito; semicélula trapeziforme-arredondada, margens laterais levemente convexas a quase retas, ápice amplamente arredondado, espessado no meio; parede celular hialina, densamente pontuada; cloroplastídio axial; pirenóides não observados.

Material examinado: BRASIL. BAHIA: Camaçari, APA Lagoas de Guarajuba, 12-I-2007, I.B. Oliveira \& I.B. Oliveira s.n. (HUEFS125505); 9-III-2007, I.B. Oliveira et al. s.n. (HUEFS125523, HUEFS125533, HUEFS125537); 8-VI-2007, I.B. Oliveira et al. s.n. (HUEFS125577); APA Rio Capivara, 12-I-2007, I.B. Oliveira \& I.B. Oliveira s.n. (HUEFS125518, HUEFS125519); 9-III-2007, I.B. Oliveira et al. s.n. (HUEFS125549, HUEFS12550); 20-VII-2007, I.B. Oliveira et al. s.n. (HUEFS125583, HUEFS125586); 20-VII-2007,I.B. Oliveira et al. s.n. (HUEFS125601). Distribuição geográfica no Brasil: Bahia (Bicudo \& Martins 1989), São Paulo (Krieger \& Gerloff 1965).

A var. borgei Krieg. \& Gerloff é distinta da variedade típica da espécie por apresentar semicélulas trapeziforme-arredondadas, ângulos basais subretangulares e ápice amplamente arredondado, com um espessamento no meio. As populações estudadas estão de acordo com a descrição, medidas e ilustrações originais apresentada por Krieger \& Gerloff (1965) para exemplares coletados no estado de São Paulo.

Cosmarium pseudopyramidatum Lundell var. maximum Börgesen, Vidensk. Meddr Naturh. Foren. Kjöbenhavn 1901: 222, pl. 7, fig. 8. 1901. Figura 45

Célula 1,7-1,8 vezes mais longa que larga, 95$111 \mu \mathrm{m}$ compr., 56-61 $\mu \mathrm{m}$ larg., istmo 16-25 $\mu \mathrm{m}$ larg., contorno ovalado, constrição mediana profunda, seno mediano linear, apertado, semicélula trapeziformearredondada, margens laterais amplamente côncavas, levemente convergentes para o ápice, margem apical amplamente arredondada, 1 pequeno espessamento 
na região mediana; parede celular hialina, densamente pontuada; cloroplastídio axial; pirenóide não observado.

Material examinado: BRASIL. BAHIA: Camaçari, APA Lagoas de Guarajuba, 12-I-2007, I.B. Oliveira \& I.B. Oliveira s.n. (HUEFS125503, HUEFS125508); 9-III-2007, I.B. Oliveira et al. s.n. (HUEFS125533, HUEFS125537, HUEFS125543); 20-VII-2007, I.B. Oliveira et al. s.n. (HUEFS125577, HUEFS125593); 25-VIII-2007, I.B. Oliveira et al. s.n. (HUEFS125617, HUEFS125620); APA Rio Capivara, 12-I-2007, I.B. Oliveira \& I.B. Oliveira s.n. (HUEFS125519); 9-III2007, I.B. Oliveira et al. s.n. (HUEFS125545); 25VIII-2007, I.B. Oliveira et al. s.n. (HUEFS125603). Distribuição geográfica no Brasil: primeiro registro da variedade para o país.

A var. maximum Börgesen difere da variedade típica da espécie por apresentar medidas celulares maiores, ápice relativamente mais acuminado e ângulos basais subquadrangulares.

Os exemplares analisados concordam com as descrições e as ilustrações apresentadas por Prescott et al. (1981) para material da América do Norte e por Krieger \& Gerloff (1965) para material da Europa.

Cosmarium pseudopyramidatum Lundell var. rotundatum Krieg. \& Gerloff, Gatt. Cosmarium 2: 129, pl. 27, fig. 3. 1965.

Figuras 46-47

Célula ca. 1,4 vezes mais longa que larga, 45-52 $\mu \mathrm{m}$ compr., 32-38 $\mu \mathrm{m}$ larg., istmo 12-15 $\mu \mathrm{m}$ larg., contorno elíptico, constrição mediana profunda, seno mediano linear, apertado, semicélula aproximadamente semicircular, margens laterais amplamente côncavas, levemente convergentes para $\mathrm{o}$ ápice, margem apical amplamente arredondada, às vezes retusa no meio, 1 pequeno espessamento na região mediana, ângulos apicais arredondados; parede celular hialina, densamente pontuada; cloroplastídio axial; pirenóide 1 .

Material examinado: BRASIL. BAHIA: Camaçari, APA Lagoas de Guarajuba, 12-I-2007, I.B. Oliveira \& I.B. Oliveira s.n. (HUEFS125508, HUEFS125509); 9-III-2007, I.B. Oliveira et al. s.n. (HUEFS125523, HUEFS125539, HUEFS125542); 8-VI-2007, I.B. Oliveira et al. s.n. (HUEFS125581); APA Rio Capivara, 9-III-2007, I.B. Oliveira et al. s.n. (HUEFS125561); 20-VII-2007, I.B. Oliveira et al. s.n. (HUEFS125589); 25-VIII-2007, I.B. Oliveira et al. s.n. (HUEFS125605).

Distribuição geográfica no Brasil: Amazonas (Lopes
\& Bicudo 2002), Mato Grosso (Krieger \& Gerloff 1965), São Paulo (Araújo \& Bicudo 2006, Taniguchi et al. 2003).

A var. rotundatum Krieg. \& Gerloff é distinta da variedade típica da espécie por apresentar célula de contorno elíptico e semicélula aproximadamente semicircular, cujo ápice tem a margem amplamente arredondada, às vezes, retusa no meio. Morfologicamente, é próxima de $C$. pyramidatum var. convexum Krieg., da qual difere por apresentar apenas um pirenóide por cloroplastídio e menores dimensões celulares.

Cosmarium pseudovariolatum Kanetsuna var. incrassatum (A.M.Scott \& Grönblad) Kanetsuna f. incrassatum, Phycol. Res. 52: 163. $2004 \equiv$ Cosmarium variolatum var. incrassatum A.M. Scott \& Grönblad, Acta Soc. Scient. Fenn. 2(8): 23, pl. 1, fig. 21-23. 1957.

Figuras 48-50

Célula ca. 1,7 vezes mais longa que larga, 51,5-54 $\mu \mathrm{m}$ compr., 30-31,5 $\mu \mathrm{m}$ larg., istmo 10-13,5 $\mu \mathrm{m}$ larg., contorno ovalado, constrição mediana moderada, seno mediano fechado; semicélula piramidal, ápice acuminado, truncado, margens laterais côncavas, convergentes no sentido do ápice, margem basal reta, margem apical arredondada, semicélula com 1 poro convexo na região mediana; parede celular hialina, pontuações grosseiras próximas do ápice e pontuações finas próximas a base; vista lateral elíptica, alongada, vista apical elíptica, 1 concavidade de ambos os lados das semicélulas; cloroplastídio axial; pirenóide não observado.

Material examinado: BRASIL. BAHIA: Camaçari, APA Lagoas de Guarajuba, 9-III-2007, I.B. Oliveira et al. s.n. (HUEFS125537, HUEFS125542); 8-VI2007, I.B. Oliveira et al. s.n. (HUEFS125581); 25VIII-2007, I.B. Oliveira et al. s.n. (HUEFS125615, HUEFS125617); APA Rio Capivara, 12-I-2007, I.B. Oliveira \& I.B. Oliveira s.n. (HUEFS125516); 9-III-2007, I.B. Oliveira et al. s.n. (HUEFS125549, HUEFS125551); 25-VIII-2007, I.B. Oliveira et al. s.n. (HUEFS125605, HUEFS125607).

Distribuição geográfica no Brasil: Brasília (Grönblad 1945 como Cosmarium variolatum var. incrassatum A.M.Scott \& Grönblad)

Cosmarium pseudovariolatum var. incrassatum f. incrassatum difere da variedade típica da espécie pela presença de um poro na região central de cada semicélula, o qual é especialmente visível em vistas lateral e apical. Segundo Kanetsuna (2004) 
a f. incrassatum é morfologicamente, próxima da f. elongatum (Scott \& Grönblad) Kanetsuna, entretanto, esta última difere por apresentar células com a relação comprimento: largura da célula da ordem de 1,8-2 vezes mais larga que longa. Os exemplares examinados concordam com a descrição e as ilustrações apresentadas por Kanetsuna (2004), embora o comprimento dos espécimes das duas APAs em estudo tenha sido maior. Optou-se por identificar os exemplares ora analisados como a f. incrassatum Kanetsuna por conta da relação comprimento/largura e da presença de margens laterais côncavas.

Cosmarium quadrifarium Lundell var. quadrifarium f. quadrifarium, Nova Acta R. Soc. Scient. Upsal. 3, 8(2): 32, pl. 3, fig. 12. 1871.

Figuras 51-52

Célula 1,2-1,3 vezes mais longa que larga, 36,5-38,5 $\mu \mathrm{m}$ compr., 27,5-30 $\mu \mathrm{m}$ larg., istmo $12-$ $13 \mu \mathrm{m}$ larg., contorno elíptico, constrição mediana moderadamente profunda, seno mediano linear, fechado; semicélula transversalmente elíptica, margens laterais amplamente arredondadas, ornadas com pontuações, margem apical retusa a levemente arredondada, ornada com verrugas; semicélula decorada com 1 intumescência na região central logo acima do istmo, formada por 1 série de grânulos arredondados; 2 séries de verrugas ao redor de toda semicélula; vista apical oblonga, 5-6 fileiras de pontuações transversais, parede celular hialina, lisa; cloroplastídios 2, axiais; pirenóides 2, 1 em cada cloroplastídio.

Material examinado: BRASIL. BAHIA: Camaçari, APA Lagoas de Guarajuba, 12-I-2007, I.B. Oliveira \& I.B. Oliveira s.n. (HUEFS125508, HUEFS125509); 9-III-2007, I.B. Oliveira et al. s.n. (HUEFS125533, HUEFS125537); 8-VI-2007, I.B. Oliveira et al. s.n. (HUEFS125574); 20-VII-2007, I.B. Oliveira et al. s.n. (HUEFS125592); APA Rio Capivara, 12-I-2007, I.B. Oliveira \& I.B. Oliveira s.n. (HUEFS125515, HUEFS125516); 9-III-2007, I.B. Oliveira et al. s.n. (HUEFS125547, HUEFS125548); 8-VI-2007, I.B. Oliveira et al. s.n. (HUEFS125566, HUEFS125582). Distribuição geográfica no Brasil: Paraná (Silva \& Cecy 2004).

Cosmarium quadrifarium var. quadrifarium $\mathrm{f}$. quadrifarium é uma espécie facilmente identificada pela forma da célula, pela intumescência basal e pela ornamentação nas vistas apical e laterais. Prescott et al. (1981) observaram quatro fileiras de verrugas na vista vertical e na vista lateral da semicélula, além de algumas escrobiculações irregulares entre os grânulos arredondados que ornamentam a intumescência facial mediana da semicélula. Essas características não foram observadas nas populações analisadas durante este estudo.

Cosmarium quadriverrucosum West \& G.S.West var. supraornatum Skuja, Acta Reg. Soc. Sci. Upsal. 14(6): 139, pl. 31, fig. 13. 1949.

\section{Figuras 53-54}

Célula tão longa quanto larga, 24-28 $\mu \mathrm{m}$ compr., 24-28 $\mu \mathrm{m}$ larg., istmo 9-12 $\mu \mathrm{m}$ larg., contorno subcircular, constrição mediana profunda, seno mediano fechado, retilíneo; semicélula subcirculares, margens laterais côncavas; ângulos apicais amplamente arredondados, margem apical retusa a amplamente arredondada; parede celular hialina a levemente acastanhada, tumor central decorado com verrugas na face da semicélula, um número variável de verrugas fileiras ao redor da semicélula, sem qualquer arranjo; cloroplastídio axial; pirenóides 2 .

Material examinado: BRASIL. BAHIA: Camaçari, APA Lagoas de Guarajuba, 12-I-2007, I.B. Oliveira \& I.B. Oliveira s.n. (HUEFS125503); 9-III-2007, I.B. Oliveira et al. s.n. (HUEFS125543); 8-VI2007, I.B. Oliveira et al. s.n. (HUEFS125579); 20VII-2007, I.B. Oliveira et al. s.n. (HUEFS125597, HUEFS125598); APA Rio Capivara, 12-I-2007, I.B. Oliveira \& I.B. Oliveira s.n. (HUEFS125518); 9-III2007, I.B. Oliveira et al. s.n. (HUEFS125545); 20 VII-2007, I.B. Oliveira et al. s.n. (HUEFS125583); 25-VIII-2007,I.B. Oliveira et al. s.n. (HUEFS125607, HUEFS125608).

Distribuição geográfica no Brasil: primeiro registro da espécie para o país.

A var. supraornatum difere da variedade típica da espécie por apresentar um número maior de verrugas no tumor da face da semicélula e uma maior quantidade de verrugas ao redor da semicélula. Morfologicamente, a var. supraornatum se parece com C. spinuliferum West \& G.S. West var. rotundatum Skuja, da qual difere por apresentar parede decorada com espinhos e, em vista apical, uma fileira de quatro verrugas de cada lado.

Cosmarium quadrum Lundell var. quadrum, Nova Acta R. Soc. Scient. Upsal. 3, 8(2): 25, pl. 2, fig. 11. 1871

Figura 55

Célula quase tão longa quanto larga, 54-68 $\mu \mathrm{m}$ compr., 52-63 $\mu \mathrm{m}$ larg., istmo 14-17 $\mu \mathrm{m}$ larg., 

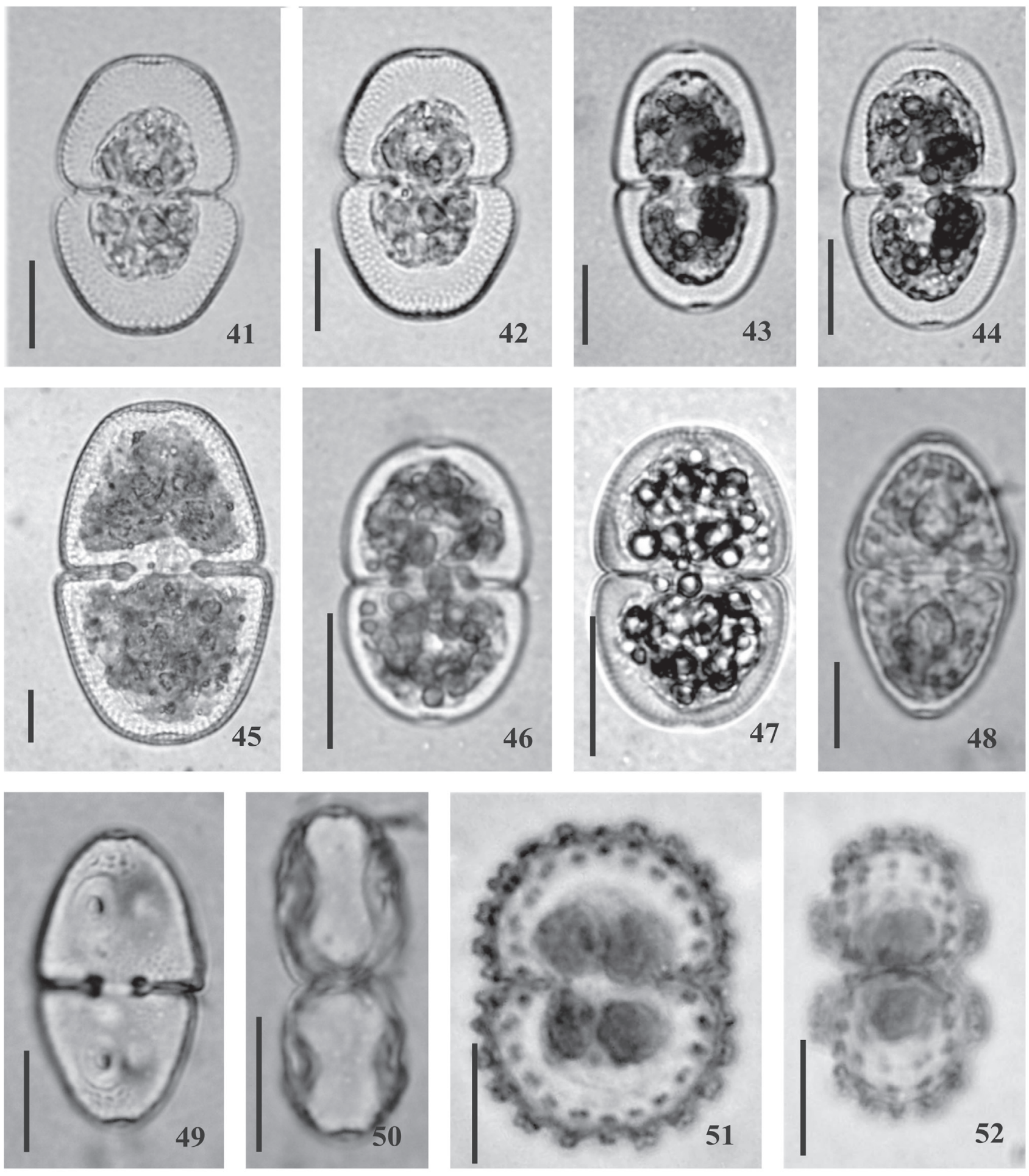

Figuras 41-52. Espécies de Cosmarium das APAs Lagoas de Guarajuba e Rio Capivara, Bahia, Brasil. 41-42. Cosmarium pseudopyramidatum var. pseudopyramidatum f. pseudopyramidatum. 43-44. C. pseudopyramidatum var. borgei. Figura 45. C. pseudopyramidatum var. maximum. 46-47. C. pseudopyramidatum var. rotundatum. 48-50. C. pseudovariolatum var. incrassatum f. incrassatum. 51-52. C. quadrifarium var. quadrifarium f. quadrifarium. Figuras 51-52 (Barras $=10 \mu \mathrm{m}) ; 41-50$ Figuras $($ Barras $=20 \mu \mathrm{m})$.

Figures 41-52. Species of Cosmarium from APA Lagoas de Guarajuba and APA Rio Capivara, Bahia, Brasil. 41-42. Cosmarium pseudopyramidatum var. pseudopyramidatum f. pseudopyramidatum. 43-44. C. pseudopyramidatum var. borgei. Figura 45. C. pseudopyramidatum var. maximum. 46-47. C. pseudopyramidatum var. rotundatum. 48-50. C. pseudovariolatum var. incrassatum f. incrassatum. 51-52. C. quadrifarium var. quadrifarium f. quadrifarium. Figures 51-52 (Barr = 10 $\mu \mathrm{m})$; 41-50 Figures $(\mathrm{Barr}=20 \mu \mathrm{m})$. 
contorno aproximadamente quadrado, constrição mediana profunda, seno mediano linear, dilatado próximo ao istmo; semicélula sub-retangular, margens laterais levemente convexas, margem apical retusa, uma leve concavidade no meio; parede celular hialina, decorada com verrugas arranjadas em fileiras verticais a levemente concêntricas, seguindo $o$ contorno da célula; cloroplastos 2, axiais; pirenóides 2 . Material examinado: BRASIL. BAHIA: Camaçari, APA Lagoas de Guarajuba, 9-III-2007, I.B. Oliveira et al. s.n. (HUEFS125534, HUEFS125539); 8-VI2007, I.B. Oliveira et al. s.n. (HUEFS125574, HUEFS125582); 20-VII-2007, I.B. Oliveira et al. s.n. (HUEFS125597); APA Rio Capivara, 12-I-2007, I.B. Oliveira \& I.B. Oliveira s.n. (HUEFS125512, HUEFS125519); 9-III-2007, I.B. Oliveira et al. s.n. (HUEFS125548, HUEFS125551); 20-VII-2007, I.B. Oliveira et al. s.n. (HUEFS125589).

Distribuição geográfica no Brasil: Amazonas (Lopes \& Bicudo 2002), Mato Grosso (De-Lamonica-Freire 1985), Rio Grande do Sul (Ungaretii 1981), São Paulo (Bicudo 1969).

Morfologicamente, a espécie lembra $C$. margaritatum, porém, esta última difere por apresentar ângulos basais arredondados e a relação comprimento/largura maior. Os exemplares descritos por Prescott et al. (1981) e De-Lamonica-Freire (1985) apresentaram medidas celulares pouco superiores (60-83 $\mu \mathrm{m}$ compr., 41-74 $\mu \mathrm{m}$ larg.) às dos exemplares analisados neste estudo. $\mathrm{O}$ material descrito e ilustrado por Lopes \& Bicudo (2002) difere dos exemplares presentemente estudados por apresentar ângulos apicais quadrangulares, margem apical reta e mais larga do que a base.

Cosmarium quadrum Lundell var. minus Nordst., Lund. Univ. Arsskr. 9(10): 11. 1873.

Figura 56

Célula ca. 1,1 vezes mais longa que larga, 35-40 $\mu \mathrm{m}$ compr., 32-38 $\mu \mathrm{m}$ larg., istmo $8-12 \mu \mathrm{m}$ larg., contorno quadrático, constrição mediana profunda, seno mediano sublinear, aberto próximo ao istmo, fechado próximo da extremidade; semicélula quadrangular, margens laterais paralelas entre si, levemente côncavas, crenuladas, margem apical retusa, 1 leve depressão na região mediana, crenulada; parede celular hialina, com verrugas de arranjo longitudinal ou obliquamente transversal; cloroplastídio axial; pirenóides 2.

Material examinado: BRASIL. BAHIA: Camaçari, APA Lagoas de Guarajuba, 12-I-2007, I.B. Oliveira
\& I.B. Oliveira S.n. (HUEFS125503, HUEFS125505, HUEFS125508); 8-VI-2007, I.B. Oliveira et al. s.n. (HUEFS125574); 20-VII-2007, I.B. Oliveira et al.s.n. (HUEFS125592); 25-VIII-2007, I.B. Oliveira et al. s.n. (HUEFS125620); APA Rio Capivara, 12-I-2007, I.B. Oliveira \& I.B. Oliveira s.n. (HUEFS125519, HUEFS125521); 9-III-2007, I.B. Oliveira et al. s.n. (HUEFS125548, HUEFS125551); 20-VII2007, I.B. Oliveira et al. s.n. (HUEFS125583); $25-$ VIII-2007, I.B. Oliveira et al. s.n. (HUEFS125607, HUEFS125605).

Distribuição geográfica no Brasil: Paraná (Felisberto \& Rodrigues 2005), São Paulo (Borge 1918).

A var. minus Nordst. em questão é muito parecida, no que tange a seus aspectos morfológicos, com a variedade típica da espécie, diferindo apenas nas menores medidas celulares e na margem apical retusa. Morfologicamente, $C$. quadrum var. minus é semelhante a $C$. subbroomei Schmidle, do qual difere por apresentar ângulos apicais arredondados e a face central da semicélula destituída de ornamentação.

Cosmarium ralfsii Bréb. var. ralfsii, in Ralfs, Brit. Desmidieae: 93, pl. 15, fig. 3. 1848.

\section{Figura 57}

Célula 1,2-1,3 vezes mais longa que larga, 112$120 \mu \mathrm{m}$ compr., 84-96 $\mu \mathrm{m}$ larg., istmo 21-26 $\mu \mathrm{m}$ larg., contorno subcircular, constrição mediana profunda, seno mediano retilíneo, fechado, aberto nos ângulos, semicélula triangular-arredondada, margens laterais lisas, côncavas, convergentes no sentido do ápice; margem apical arredondada; parede celular hialina, finamente pontuada; vista lateral subcircular; vista apical elíptica; cloroplastídio parietal, lobado; pirenóides pequenos, vários, distribuídos no cloroplastídio sem qualquer arranjo.

Material examinado: BRASIL. BAHIA: Camaçari, APA Lagoas de Guarajuba, 9-III-2007, I.B. Oliveira et al. s.n. (HUEFS125523); 8-VI-2007, I.B. Oliveira et al. s.n. (HUEFS125579); 20-VII-2007, I.B. Oliveira et al. s.n. (HUEFS125592), 25-VIII-2007, I.B. Oliveira et al. s.n. (HUEFS125617); APA Rio Capivara, 9-III-2007, I.B. Oliveira et al. s.n. (HUEFS125561); 8-VI-2007, I.B. Oliveira et al. s.n. (HUEFS125571); 20-VII-2007, I.B. Oliveira et al. s.n. (HUEFS125589); 25-VIII-2007, I.B. Oliveira et al. s.n. (HUEFS125605).

Distribuição geográfica no Brasil: São Paulo (Araújo \& Bicudo 2006, Bicudo 1969).

Quanto à morfologia celular, Cosmarium ralfsii var. ralfsii é semelhante a $C$. pachydermum e $C$. 
lundellii Delponte var. lundellii, diferindo do primeiro por apresentar istmo mais largo, semicélula ovalada e dois pirenóides centrais no cloroplastídio; e do segundo, por apresentar semicélulas infladas, de contorno triangular-arredondado, porém, mais achatado e vista apical ovalada, com uma leve inflação mediana. West \& West (1905) descreveram o cloroplastídio da espécie como sendo parietal, com o que concordamos. Contudo, Lütkemüller (1910) e Carter (1920) descreveram o plastídio como sendo axial, com lamelas verticais radiantes de um eixo comum.

Cosmarium regnesii Reinsch var. regnesii, Abh. Senckenberg Naturf. Ges. 6: 116, pl. 22, fig. A III: 1-5. 1876b.

Figuras 58-61

Célula ca. 1,2 vezes mais longa que larga, (7,5)12,5-14,5 $\mu \mathrm{m}$ compr., (5-)10-12,5 $\mu \mathrm{m}$ larg., istmo (2,5-)4-5,5 $\mu \mathrm{m}$ larg., contorno subquadrangular, constrição mediana profunda, seno mediano aberto, linear ou em forma de semicírculo; semicélula oblonga a sub-retangular, margem apical convexa até quase reta, 2 dentículos na proximidade dos ângulos, margens laterais côncavas, margens basais levemente convexas, lisas, divergentes para o ápice; parede celular hialina a acastanhada, 3 projeções, 1 no centro da semicélula e 2 em cada lado; cloroplastídio axial; pirenóide 1, central.

Material examinado: BRASIL. BAHIA: Camaçari, APA Lagoas de Guarajuba, 12-I-2007, I.B. Oliveira \& I.B. Oliveira s.n. (HUEFS125507); 9-III-2007, I.B. Oliveira et al. s.n. (HUEFS125532, HUEFS125534); 20-VII-2007, I.B. Oliveira et al. s.n. (HUEFS125592, HUEFS125597); 25-VIII-2007, I.B. Oliveira et al. s.n. (HUEFS125620); APA Rio Capivara, 12-I-2007, I.B. Oliveira \& I.B. Oliveira s.n. (HUEFS125512, HUEFS125516); 9-III-2007, I.B. Oliveira et al. s.n. (HUEFS125546, HUEFS125550); 20-VII2007, I.B. Oliveira et al. s.n. (HUEFS125584); 20VII-2007, I.B. Oliveira et al. s.n. (HUEFS125583, HUEFS125601).

Distribuição geográfica no Brasil: Paraná (Felisberto \& Rodrigues 2008)

Os exemplares atualmente identificados com C. regnesii var. regnesii diferem das ilustrações apresentadas por Croasdale \& Flint (1988), pois estas mostram a célula com a margem apical retusa e as laterais com três pequenas elevações. Prescott et al. (1981) ilustraram a espécie na pl. 258, fig. 2-4; uma análise detalhada dessas figuras permitiu concluir que pertencem a três táxons distintos e que só a fig.
3 realmente ilustra $C$. regnesii var. regnesii. Prescott et al. (1981) comentaram que as populações descritas para o Brasil apresentavam células com a lóbulos apicais e laterais reduzidos, concordando com o material analisado no presente estudo.

Cosmarium reniforme (Ralfs) W. Archer var. reniforme f. reniforme, Journ. Bot. 12: 92. 1874. Figura 62

Célula 1,2-1,3 vezes mais longa que larga, 62$70 \mu \mathrm{m}$ compr., 48-56,5 $\mu \mathrm{m}$ larg., istmo 12-15 $\mu \mathrm{m}$ larg., contorno subquadrangular, constrição mediana profunda, seno mediano sublinear, fechado em sua maior extensão, aberto próximo das extremidades; semicélula reniforme, margens laterais paralelas entre si, levemente côncavas, crenuladas, margem apical amplamente arredondada, crenulada; parede celular hialina, verrugas dispostas em fileiras horizontais e verticais; cloroplastídios 2-radiados, axiais; pirenóides 2 .

Material examinado: BRASIL. BAHIA: Camaçari, APA Lagoas de Guarajuba, 12-I-2007, I.B. Oliveira \& I.B. Oliveira s.n. (HUEFS125504); 8-VI-2007, I.B. Oliveira et al. s.n. (HUEFS125577); 8-VI-2007, I.B. Oliveira et al. s.n. (HUEFS125577); 20-VII-2007, I.B. Oliveira et al. s.n. (HUEFS125597); 25-VIII2007, I.B. Oliveira et al. s.n. (HUEFS125615); APA Rio Capivara, 12-I-2007, I.B. Oliveira \& I.B. Oliveira s.n. (HUEFS125516); 9-III-2007, I.B. Oliveira et al. s.n. (HUEFS125550); 20-VII-2007, I.B. Oliveira et al. s.n. (HUEFS125597); 25-VIII-2007, I.B. Oliveira et al. s.n. (HUEFS125604).

Distribuição geográfica no Brasil: Amazonas (Melo \& Souza 2009, Förster 1969), Goiás (Felisberto \& Rodrigues 2004), Paraná (Cetto et al. 2004).

Cosmarium reniforme var. reniforme f. reniforme é uma espécie facilmente identificada por possuir células de contorno subquadrangular e semicélulas reniformes. Morfologicamente, é próxima de C. intermedium Delponte var. intermedium e C. margaritiferum Menegh. var. margaritiferum f. margaritiferum, contudo difere da primeira por apresentar as margens laterais aconcavadas e convergentes para o ápice e ângulos basais arredondados; e da segunda, por apresentar margem apical reta e escrobiculações entre as verrugas presentes no centro da semicélula. Segundo West \& West (1908), o arranjo e a disposição dos grânulos que ornamentam a parede celular podem ser bem variados, podendo se apresentar em fileiras verticais, horizontais, diagonais ou mesmo irregulares. 

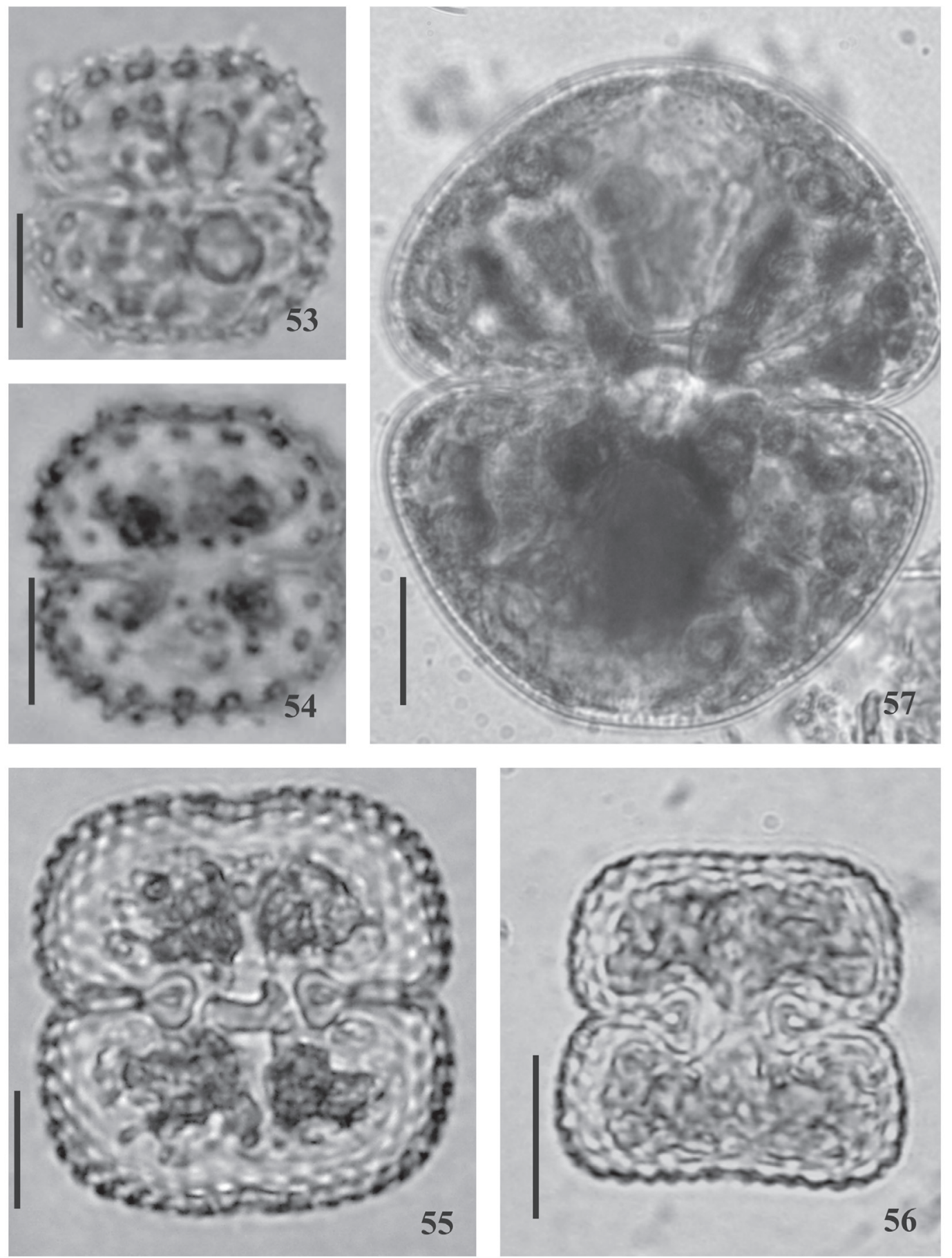
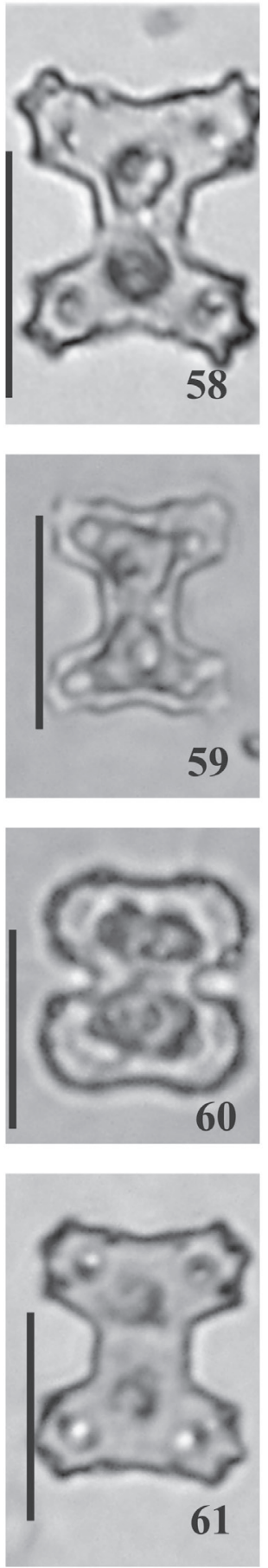

Figuras 53-61. Espécies de Cosmarium das APAs Lagoas de Guarajuba e Rio Capivara, Bahia, Brasil. 53-54. Cosmarium quadriverrucosum var. supraornatum. 55. C. quadrum var. quadrum. 56. C. quadrum var. minus. 57. C. ralfsii var. ralfsii. 58-61. C. regnesii var. regnesii (variações morfológicas da célula). Figuras 53-54, 58-61 (Barras =10 $\mu \mathrm{m})$; 55-57 Figuras (Barras =20 $\mu \mathrm{m})$.

Figures 53-61. Species of Cosmarium from APA Lagoas de Guarajuba and APA Rio Capivara, Bahia, Brasil. 53-54. Cosmarium quadriverrucosum var. supraornatum. 55. C. quadrum var. quadrum. 56. C. quadrum var. minus. 57. C. ralfsii var. ralfsii. 58-61. C. regnesii var. regnesii (morfological variations of cell). Figures 53-54, 58-61 (Barr $=10 \mu \mathrm{m})$; 55-57 Figures $($ Barr $=20 \mu \mathrm{m})$. 
Cosmarium regulare Schmidle, Flora 78: 57, pl. 7, fig. 16. 1894.

Figura 63

Célula tão longa quanto larga, 34-40 $\mu \mathrm{m}$ compr., 34-40 $\mu \mathrm{m}$ larg., istmo 10-12 $\mu \mathrm{m}$ larg., contorno aproximadamente circular, constrição mediana profunda, seno mediano linear, fechado, dilatado na extremidade; semicélula elíptica, margens lateral e apical lisas, laterais côncavas, convergindo para o ápice, ápice retuso a amplamente arredondado; parede celular hialina, pontuada, pontuações distribuídas em 1 série subapical e outra série transversal, na região mediana da célula, pontuações aleatórias nas margens laterais; cloroplastídios 2, axiais; pirenóides 4-5.

Material examinado: BRASIL. BAHIA: Camaçari, APA Lagoas de Guarajuba, 8-VI-2007, I.B. Oliveira et al. s.n. (HUEFS125574, HUEFS125577, HUEFS125582); 25-VIII-2007, I.B. Oliveira et al. s.n. (HUEFS125615); APA Rio Capivara, 12-I-2007, I.B. Oliveira \& I.B. Oliveira s.n. (HUEFS125518); 9-III-2007, I.B. Oliveira et al. s.n. (HUEFS125545); 20-VII-2007, I.B. Oliveira etal. s.n. (HUEFS125583); 25-VIII-2007,I.B. Oliveira et al. s.n. (HUEFS125605, HUEFS125607).

Distribuição geográfica no Brasil: Goiás (Felisberto \& Rodrigues 2004).

Morfologicamente, C. regulare Schmidle se assemelha a $C$. depressum (Nägeli) Lundell var. depressum f. depressum e a C. stigmosum (Nordst.) Krieg. Difere do último por apresentar a parede celular completamente pontuada e de $C$. depressum (Nägeli) Lundell var. depressum f. depressum por apresentar medidas celulares proporcionalmente maiores e semicélulas oblongas, com margem apical quase reta.

Cosmarium securiforme Borge var. brasiliense Grönblad, Acta Soc. Sci. Fenn., sér. B, 2(6): 21, fig. 140. 1945.

Figura 64

Célula 1-1,2 vezes mais larga que longa, 115-116 $\mu \mathrm{m}$ compr., 127,5-128,5 $\mu \mathrm{m}$ larg., istmo 29-30,5 $\mu \mathrm{m}$ larg., contorno aproximadamente circular, constrição mediana profunda, seno mediano aberto, angular; semicélula ovalada, acuminada, margens basais levemente côncavas, margens laterais levemente convexas, margem apical amplamente arredondada, ângulos basais agudos, terminando em 1 bifurcação curta, pouco voltada para cima; parede celular hialina, finamente pontuada; vista apical fusiforme,
2 pequenos espinhos em cada pólo; vista lateral não observada; cloroplastídios 8 , parietais, preenchendo todo espaço celular; pirenóides vários, pequenos, esparsos.

Material examinado: BRASIL. BAHIA: Camaçari, APA Lagoas de Guarajuba, 12-I-2007, I.B. Oliveira \& I.B. Oliveira s.n. (HUEFS125505, HUEFS125507, HUEFS125508); 25-VIII-2007, I.B. Oliveira et al. s.n. (HUEFS125620); APA Rio Capivara, 12-I-2007, I.B. Oliveira \& I.B. Oliveira s.n. (HUEFS125516); 25VIII-2007, I.B. Oliveira et al. s.n. (HUEFS125607, HUEFS125608).

Distribuição geográfica no Brasil: Goiás (Förster 1964), Pará (Grönblad 1945).

Grönblad (1945) descreveu a var. brasiliense com base em material coletado no estado do Pará. Esta variedade difere da variedade típica da espécie por apresentar dois ou três espinhos nos ângulos laterais, seno linear fechado e ápices dos ângulos laterais agudos. Na descrição original da variedade, Grönblad (1945) incluiu medidas celulares pouco inferiores (99-110 $\mu \mathrm{m}$ compr., 106-125 $\mu \mathrm{m}$ larg.) do que as obtidas das populações deste estudo. Förster (1964) identificou para Conceição, estado de Goiás, representantes de uma "forma maior" (nome sem significado de entidade taxonômica, mas referindo a expressões morfológicas), exemplares cujas medidas celulares foram de 129-136 $\mu \mathrm{m}$ compr. e 149-158 $\mu \mathrm{m}$ larg., ou seja, valores superiores aos encontrados neste estudo; contudo, as ilustrações são idênticas às dos exemplares analisados.

Cosmarium sphalerostichum Nordst. var. sphalerostichum f. bituberculatum Först., Revue Algol. 1963: 75. pl. 5, fig. 27, pl. 9, fig. 10. 1963. Figuras 65-66

Célula ca. 1,4 vezes mais larga que longa, 25$28 \mu \mathrm{m}$ compr., 18-20 $\mu \mathrm{m}$ larg., istmo 8-10 $\mu \mathrm{m}$ larg., contorno subquadrangular, constrição mediana profunda, seno mediano estreito, semicélula oblonga, margens laterais côncavas, margem apical amplamente arredondada, quase reta, 3-4 séries de verrugas ao redor da semicélula; parede celular hialina, 2 verrugas maiores localizadas subapicalmente; vista apical ovalada, 2 pequenas proeminências de cada lado da célula; vista lateral oblonga, 1 proeminência de cada lado; cloroplastídio parietal; pirenóide não observado.

Material examinado: BRASIL. BAHIA: Camaçari, APA Lagoas de Guarajuba, 8-VI-2007, I.B. Oliveira et al. s.n. (HUEFS125579, HUEFS125581); 25-VIII- 
2007, I.B. Oliveira et al. s.n. (HUEFS125617); APA Rio Capivara, 8-VI-2007, I.B. Oliveira et al. s.n. (HUEFS12571, HUEFS125584).

Distribuição geográfica no Brasil: Roraima (Förster 1963).

Förster (1963), ao propor a f. bituberculatum, diferiu-a da forma típica da espécie por apresentar duas verrugas maiores localizadas abaixo da margem superior das semicélulas e istmo relativamente mais estreito. Morfologicamente, Cosmarium sphalerostichum var. sphalerostichum f. bituberculatum Först. se parece com $C$. bipunctatum Börgense var. maius Först., no entanto, o último é diferente por apresentar semicélulas subtrapeziformes, ângulos basais subquadrangulares e duas verrugas maiores localizadas facialmente, na região central da semicélula.

Cosmarium subretusiforme West \& G.S.West, J. Roy. Micr. Soc. 1894: 5, pl. 1, fig. 20. 1894. Figura 67

Célula ca. 1,4 vezes mais longa que larga, 13$16 \mu \mathrm{m}$ compr., 10-12 $\mu \mathrm{m}$ larg., lobo apical 7-8,5 $\mu \mathrm{m}$ larg., istmo 6-7,5 $\mu \mathrm{m}$ larg., contorno sub-retangular, constrição mediana curta, seno mediano aberto, obtuso; semicélula subquadrangular, margens laterais fortemente côncavas, depois paralelas entre si no terço superior da semicélula, margem apical retusa; parede celular hialina, lisa; cloroplastídio axial; pirenóide não observado.

Material examinado: BRASIL. BAHIA: Camaçari, APA Lagoas de Guarajuba, 9-III-2007, I.B. Oliveira et al. s.n. (HUEFS125537, HUEFS125539, HUEFS125542); 8-VI-2007, I.B. Oliveira et al. s.n. (HUEFS125577, HUEFS125582); 20-VII-2007, I.B. Oliveira et al. s.n. (HUEFS125596, HUEFS125597); APA Rio Capivara, 9-III-2007, I.B. Oliveira et al. s.n. (HUEFS125547, HUEFS125549); 25-VIII-2007, I.B. Oliveira et al. s.n. (HUEFS125604).

Distribuição geográfica para o Brasil: Amazonas (Thomasson 1971).

Conforme West \& West (1905), C. subretusiforme é bastante próximo, nos seus aspectos morfológicos, de $C$. retusiforme (Wille) Gutw., entretanto, difere deste último por apresentar a célula relativamente menor e possuir a vista apical com lados quase retos.

Cosmarium trilobulatum Reinsch var. abscissum (Schmidle) Krieg. \& Gerloff, Gatt. Cosmarium 1: 99, pl. 21, fig. $1.1962 \equiv$ Cosmarium hammeri Reinsch f. abscissa Schmidle, Nova Hedwigia 34:
302, pl. 4, fig. 8. 1895.

Figura 68

Célula 1-1,25 vezes mais longa que larga, 25$29 \mu \mathrm{m}$ compr., 20-28 $\mu \mathrm{m}$ larg., istmo 5-7,5 $\mu \mathrm{m}$ larg., contorno elíptico, constrição mediana profunda, seno mediano linear, estreito, dilatado no ápice; semicélulas trilobadas, irregularmente hexagonais, ângulos basais sub-retangular-arredondados, margens laterais inferiores muito levemente divergentes, retusas na parte média, margens laterais superiores aconcavadas, margem superior truncada, reta ou muito suavemente convexa, margens laterais levemente intumescidas; parede celular hialina, lisa; vista vertical elíptica, 3 pequenas verrugas na região mediana da célula; cloroplastídio axial; pirenóide não observado.

Material examinado: BRASIL. BAHIA: Camaçari, APA Lagoas de Guarajuba, 8-VI-2007, I.B. Oliveira et al. s.n. (HUEFS125503); 9-III-2007, I.B. Oliveira et al. s.n. (HUEFS125533, HUEFS125537, HUEFS125543); 8-VI-2007, I.B. Oliveira et al. s.n. (HUEFS125582), 25-VIII-2007, I.B. Oliveira et al. s.n. (HUEFS125615); APA Rio Capivara, 12-I-2007, I.B. Oliveira \& I.B. Oliveira s.n. (HUEFS125516, HUEFS125518); 9-III-2007, I.B. Oliveira et al. s.n. (HUEFS1255345, HUEFS125551); 20-VII2007, I.B. Oliveira et al. s.n. (HUEFS125584, HUEFS125601); 25-VIII-2007, I.B. Oliveira et al. s.n. (HUEFS125603, HUEFS125605).

Distribuição geográfica no Brasil: Paraná (Silva \& Cecy 2004, Bittencourt-Oliveira 1993).

A var. abscissum (Schmidle) Krieg. \& Gerloff difere da típica da espécie por apresentar margens laterais divergentes e subparalelas entre si, lobo apical largo e curto, além da vista lateral da semicélula cônico-truncada. Esta variedade lembra, quanto à sua morfologia, Cosmarium pseudoretusum Duc. var. africanum (F.E.Fritsch) Krieg. \& Gerloff, que apresenta o lobo superior mais projetado, os ângulos basais arredondados, com papilas e a vista apical com a região mediana inflada.

Cosmarium variolatum P.Lundell var. variolatum, Nova Acta. R. Soc. Sci. Upsal. 3(8): 2, 41, pl. 2, fig. 19, 1871.

Figura 69

Célula 1,5-1,6 vezes mais longa que larga, 30$35 \mu \mathrm{m}$ compr., 18-22 $\mu \mathrm{m}$ larg., istmo 5-7 $\mu \mathrm{m}$ larg., contorno ovalado, constrição mediana profunda, seno mediano linear, fechado em quase toda extensão, levemente dilatado no ápice; semicélula piramidal- 

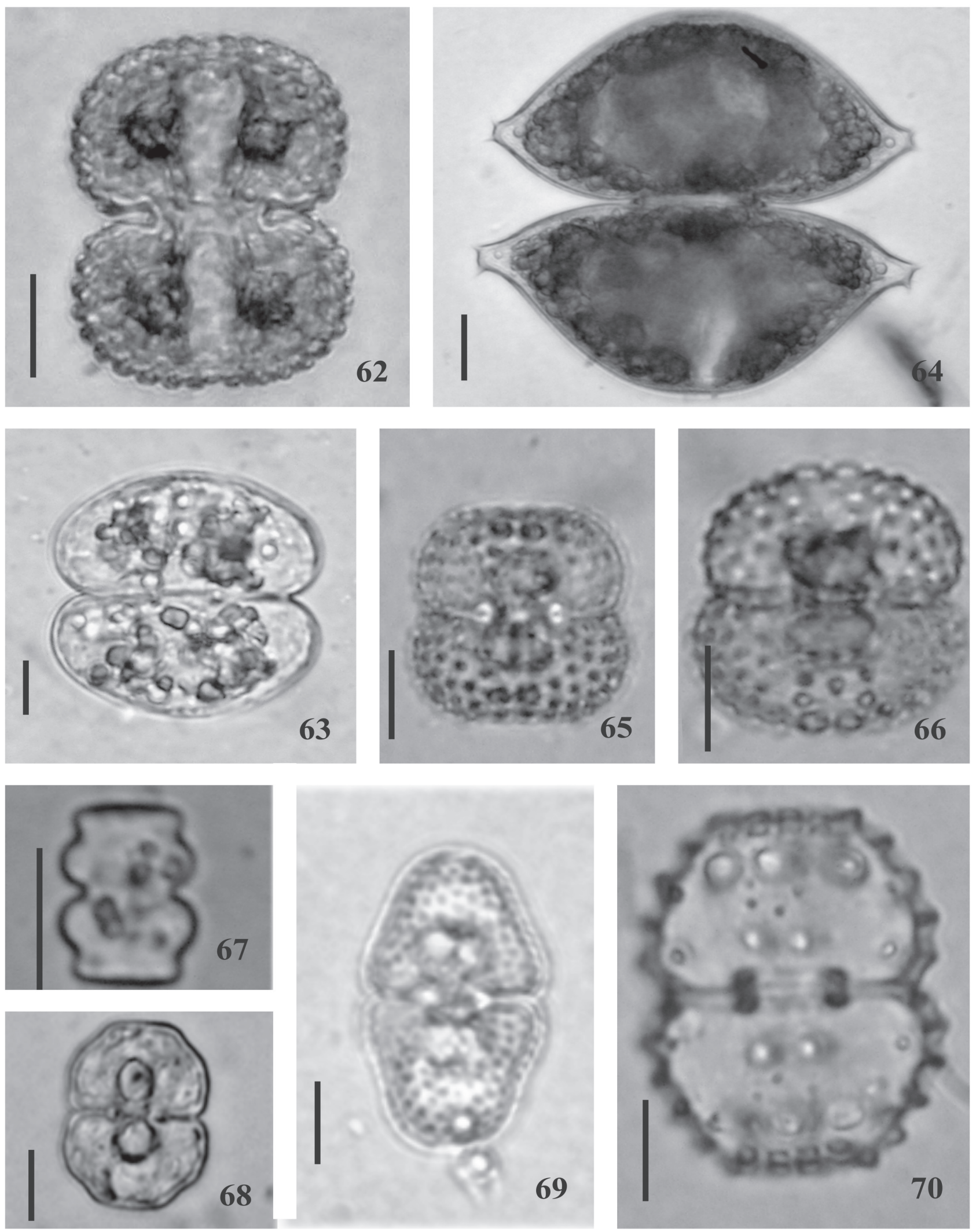

Figuras 62-70. Espécies de Cosmarium das APAs Lagoas de Guarajuba e Rio Capivara, Bahia, Brasil. 62. Cosmarium reniforme var. reniforme f. reniforme. 63. C. regulare. 64. C. securiforme var. brasiliense. 65-66. C. sphalerostichum var. sphalerostichum $\mathrm{f}$. bituberculatum. 67. C. subretusiforme. 68. C. trilobulatum var. abscissum. 69. C. variolatum var. variolatum. 70. C. vitiosum. Figuras 62, 64, 69-70 $($ Barras $=10 \mu \mathrm{m})$; Figuras 63, 65-68 $($ Barras $=20 \mu \mathrm{m})$.

Figures 62-70. Species of Cosmarium from APA Lagoas de Guarajuba and APA Rio Capivara, Bahia, Brasil. 62. Cosmarium reniforme var. reniforme f. reniforme. 63. C. regulare. 64. C. securiforme var. brasiliense. 65-66. C. sphalerostichum var. sphalerostichum f. bituberculatum. 67. C. subretusiforme. 68. C. trilobulatum var. abscissum. 69. C. variolatum var. variolatum. 70. C. vitiosum. Figures 62, 64, 69-70 $($ Barr $=10 \mu \mathrm{m})$; Figures 63, 65-68 $($ Barr $=20 \mu \mathrm{m})$. 
truncada, margens lateral e apical lisas, laterais convexas, convergindo para o ápice, ápice retusotruncado; parede celular hialina, escrobiculada; cloroplastídio axial; pirenóide 1, central.

Material examinado: BRASIL. BAHIA: Camaçari, APA Lagoas de Guarajuba, 12-I-2007, I.B. Oliveira \& I.B. Oliveira s.n. (HUEFS125503, HUEFS125509, HUEFS125510); 9-III-2007, I.B. Oliveira et al. s.n. (HUEFS125537, HUEFS125543); 20-VII-2007, I.B. Oliveira et al. s.n. (HUEFS125596, HUEFS125597); 25-VIII-2007,I.B. Oliveira et al. s.n. (HUEFS125615, HUEFS125617); APA Rio Capivara, 12-I-2007, I.B. Oliveira \& I.B. Oliveira s.n. (HUEFS125516, HUEFS125512, HUEFS125519); 9-III-2007, I.B. Oliveira et al. s.n. (HUEFS125521, HUEFS125548, HUEFS125550); 20-VII-2007, I.B. Oliveira et al. s.n. (HUEFS125586); 25-VIII-2007, I.B. Oliveira et al. s.n. (HUEFS125603, HUEFS125604, HUEFS125608).

Distribuição geográfica no Brasil: primeiro registro da espécie para o país.

Morfologicamente $C$. variolatum var. variolatum se parece com C. pseudopyramidatum do qual difere por apresentar células relativamente menores e parede celular densamente escrobiculada. Os exemplares ora analisados concordam com as descrições, medidas e ilustrações apresentadas por West \& West (1905) para material da Inglaterra e por Croasdale \& Flint (1988) para material da Nova Zelândia.

Cosmarium vitiosum A.M. Scott \& Grönblad, Acta Soc. Scient. Fenn. 2(8): 24, pl. 9, fig. 1-3. 1957. Figura 70

Célula 1,1-1,2 vezes mais longa que larga, 35,5-37,5 $\mu \mathrm{m}$ compr., 30-32,5 $\mu \mathrm{m}$ larg., istmo 6-7,5 $\mu \mathrm{m}$ larg., contorno elíptico-truncado, constrição mediana profunda, seno mediano linear, fechado, extremidades arredondadas; semicélula trapeziforme, margens laterais amplamente côncavas, margem apical reta, ornada com 4 pequenas verrugas, parede celular acastanhada, ornada com verrugas, 1 série de 3 verrugas maiores logo abaixo da margem apical, 1 série de 2 verrugas na região mediana da semicélula, logo acima do istmo, além de pontuações entre as verrugas; vista apical elíptica com 3 proeminências de cada lado da semicélula; vista lateral oblonga com 1 proeminência de cada lado da semicélula; cloroplastídio axial; pirenóide 1, central.

Material examinado: BRASIL. BAHIA: Camaçari, APA Lagoas de Guarajuba, 12-I-2007, I.B. Oliveira \& I.B. Oliveira s.n. (HUEFS125504, HUEFS125507); 9-III-
2007, I.B. Oliveira et al. s.n. (HUEFS125577); 20VII-2007, I.B. Oliveira et al. s.n. (HUEFS125592); 25-VIII-2007, I.B. Oliveira et al. s.n. (HUEFS125615, HUEFS125617, HUEFS125620); APA Rio Capivara, 12-I-2007, I.B. Oliveira \& I.B. Oliveira s.n. (HUEFS125515, HUEFS125519); 9-III-2007, I.B. Oliveira et al. s.n. (HUEFS125547, HUEFS125561, HUEFS125566); 20-VII-2007, I.B. Oliveira et al. s.n. (HUEFS125583, HUEFS125586), 25-VIII-2007, I.B. Oliveira et al. s.n. (HUEFS125604, HUEFS125607, HUEFS125608).

Distribuição geográfica no Brasil: Mato Grosso (DeLamonica-Freire 1985).

Cosmarium vitiosum é de identificação relativamente fácil por apresentar as seguintes características: (1) semicélula trapeziforme, (2) face da semicélula ornada com quatro pequenas verrugas e (3) uma série de três verrugas maiores situadas logo abaixo da margem apical e uma outra série, porém, de duas verrugas situadas na região mediana da semicélula, logo acima do istmo, com pontuações entre estas. Considerada sua morfologia, $C$. vitiosum lembra C. subpraemorosum Borge, porém, este último é distinto por apresentar três fileiras de verrugas ao redor da célula e três verrugas maiores no centro da célula, distribuídas de maneira linear, além de dois pirenóides.

\section{Agradecimentos}

À Coordenação de Aperfeiçoamento de Pessoal do Ensino Superior, pela concessão da Bolsa de Mestrado à primeira autora; à Universidade Estadual de Feira de Santana e ao Instituto de Botânica da Secretaria do Meio Ambiente do Estado de São Paulo, pelo apoio logístico; ao Programa de Pós-Graduação em Botânica da UEFS, pelo auxílio financeiro concedido para a realização das coletas.

\section{Referências bibliográficas}

Agujaro, L.F. 1990. Ficoflórula epífita em "Spirodela oligorrhiza" (Lemnaceae) de um tanque artificial no município de São Paulo, SP. Dissertação de Mestrado em Ciências Biológicas, Botânica, Universidade Estadual Paulista, Rio Claro.

Araújo, A. \& Bicudo, C.E.M. 2006. Criptógamos das Fontes do Ipiranga, São Paulo, SP. Algas 22. Zygnemaphyceae (gêneros Actinotaenium, Cosmarium e Heimancia). Hoehnea 33: 219-237. 
Bernard, C. 1909. Sue quelques algues unicellularires d'eau douce. Recoltées dans Le domaine Malais. Departament de l'agriculture aux indesnéerlanaises, Landsdrukkerij.

Bicudo, C.E.M. 1969. Contribution to the knowledge of the state of São Paulo, Brazil (including from the state of Minas Gerais). Nova Hedwigia 17: 443-549.

Bicudo, C.E.M. \& Ungaretti, I. 1986. Desmídias da lagoa-represa Águas Belas, Rio Grande do Sul, Brasil. Revista Brasileira deBiologia 46:285-307.

Bicudo, C.E.M. \& Martins, D.V. 1989. Desmídias (Zygnemaphyceae) de Itanagra, estado da Bahia, Brasil. Revista Brasileira de Biologia 49: 309-324.

Bicudo, C.E.M. \& Menezes, M. 2006. Gêneros de algas de águas continentais do Brasil: chave para identificação e descrições. 2 ed. RiMa, São Carlos.

Bittencourt-Oliveira, M.C. 1993. Ficoflórula do Rio Tibagi, Estado do Parana, Brasil, IIII: Gêneros Actinotaenium, Cosmarium e Staurodesmus (Zygnemaphyceae). Semina, 14: 86-95.

Bittencourt-Oliveira, M.C. 2002. A comunidade fitoplanctônica do rio Tibagi: uma abordagem preliminar de sua biodiversidade. In: M.E. Medry, E. Biachini, O.A. Shibatta \& J.A. Pimenta (orgs.). A bacia do rio Tibagi. Londrina, pp. 337-402.

Borge, O. 1903. Die Algen der ersten Regnellschen Expedition, 2: Desmidiaceae. Arkiv för Botanik. 1: 71-138.

Borge, O. 1918. Die von Dr. A. Löfgren in São Paulo gessammelten Süsswasseralgen. Arkiv för Botanik 15: 1-108.

Brook, A.J. 1981. The Biology of Desmids. Oxford: Berkwell, Scientific Public. University of California Press.

Carter, N. 1920. Studies on the chloroplasts of Desmids: the chloroplast of Cosmarium. Annals of Botany, 34(134): 265-285.

Cetto, J.M.L., J.A. Felisberto, S.A. \& Rodrigues, L. 2004. Comunidade de algas perifíticas no reservatório de Irai, Estado do Paraná, Brasil. Acta Scientiarum, Biological Sciences, 26: 1-7.

Croasdale, H. \& Flint, E.A. 1988. Flora of the New Zealand: freshwater algae, Chlorophyta, Desmids with comments on their habitats. v. 2 . DSIR, Botany Division, Chistchurch.

De-Lamonica-Freire, E.M. 1985. Desmidioflorula da estação ecológica da Ilha de Taiamã, município de Cárceres, Mato Grosso, Brasil. Tese de Doutorado, Universidade de São Paulo, São Paulo.

Delazari-Barroso, A., Sant'anna, C.L. \& Senna, P.A.C. 2007. Phytoplankton from Duas Bocas Reservoir, Espírito Santo State, Brazil (except diatoms). Hoehnea 34: 211-229.

Felisberto, S.A. \& Rodrigues, L. 2004. Periphytic Desmids in Corumbá Reservoir, Goiás, Brazil: genus Cosmarium Corda. Brazilian Journal of Biology, 64: 141-150.

Felisberto, S.A. \& Rodrigues, L. 2005. Influência do gradiente longitudinal rio-barragem na similaridade da assembléia de Desmídias perifíticas. Revista Brasileira de Botânica, 28: 241-254.

Felisberto,S.A.\&Rodrigues,L.2008.Desmidiaceae, Gonatozygaceae e Mesotaeniaceae na comunidade perifítica do reservatório de Salto do Vau (Bacia do rio Iguaçu, PR). Hoehnea, 35: 235-254.

Förster, K. 1963. Desmidiaceen aus Brasilien. 1. Nord-Brasilien. Revue Algologie 7: 38-92.

Förster, K. 1964. Desmidiaceen aus Brasilien 2, Teil: Bahia, Goyaz. Phiuhy und NordBrasilien. Hydrobiologia, Acta Hydrobiologica Hydrographica et Protistologica. Fas.3-4, XXII, p. 321-505, pl. 1-51.

Förster, K. 1969. Amazonische desmidien, 1. Amazoniana 2: 5-116.

Förster, K. 1974. Amazonische desmidien, 2. Amazoniana 2: 135-242.

Förster, K. 1982. Das Phytoplankton des Sudanessers, Conjugatophyceae, Zygnematales und Desmidiales (excl. Zygnemataceae), Band XVI, Teil 8, Halfte 1, 1-593. E. Scheizerbort'sche Verlagsbuchhandlung, Stuttgart.

Franceschini, L.M. 1992. Algues d'eau douce de Porto Alegre, Brésil (les Diatomophycées exclues). Bibliotheca Phycologica B 92: 1-81.

Grönblad, R. 1945. De algus brasiliensibus: praecipue Desmidiacius, in regione inferiore fluminis Amazonas. Acta Societatis Scientiarum Fennicae, nov., ser. B 2: 1-43.

Grönblad, R. 1960. Contributions to the knowledge of the freshwater algae of Italy. Acta Societatis Scientiarum Fennicae 22: 1-85.

Huszar, V. \& Silva, L.H.S. 1992. Comunidades fitoplanctônicas de quatro lagoas costeiras do norte do Estado do Rio de Janeiro, Brasil. Acta Limnologica Brasiliensia 4: 291-314. 
Kanetsuna, Y. 2004. New and interesting desmids (Zygnematales, Chlorophyceae) collected from Brazil and Argentina. Phycological Research 52: 160-167.

Krieger, W. \& Gerloff, J. 1965. Die Guttung Cosmarium. Weinheim: J. Cramer, 2: 113-240.

Lima, M.G.S.M. 1982. Desmidiaceae (Zygnemaphyceae) do município do Rio de Janeiro e arredores: uma contribuição ao seu conhecimento. Rio de Janeiro Dissertação de Mestrado. Universidade Federal do Rio de Janeiro, Rio de Janeiro.

Ling, H.U. \& Tyler, P.A. 1985. Freshwater algae, exclusive of diatoms, of the Alligator rivers region, northern territory. University of Tasmania. Australia.

Lopes, M.R.M. \& Bicudo, C.E.M. 2002. Desmidioflórula de um lago da planície de inundação do Rio Acre, Estado do Amazonas, Brasil. Acta Amazonica 33: 167-212.

Lütkemmüler, J. 1910. Zur kenntnis der Desmidiaceen Böhmens. Verh. K. K. Zoo. Bot. Ges. Wien 560: 478-503.

Marinho, M.M. \& Sophia, M.G. 1997. Desmidioflórula do açude do Jacaré, município de Moji-Guaçu, SP, Brasil. Hoehnea 24: 37-53.

Martins, D.V. \& Bicudo, C.E.M. 1987. Desmídias da Ilha de Itanharé, estado da Bahia, Brasil. Revista Brasileira de Biologia 47: 1-16.

Melo, S. \& Souza, K.F. 2009. Flutuação anual e interanual da riqueza de espécies de desmídias (Chlorophyta - Conjugatophyceae) em um lago de inundação amazônico de águas pretas (Lago Cutiuaú, Estado do Amazonas, Brasil). Acta Scientiarum, Biological Sciences 31: 235-243.

Nordstedt, C.F.O. 1869. Symbolae ad florem Brasiliae centrals congnoscedam. Öfversigt af Kungliga Vetenskapsakademiens förhandlingar 3: 195-234.

Nordstedt, O. 1877. Nonnullae algae aquae dulcis brasilienses. Vidensk. Meddr natuth. Foren. Kjöbenhavn 3: 15-29.

Oliveira, I.B., Moura, C.W.N. \& Bicudo, C.E.M. 2009. Micrasterias C. Agardh ex Ralfs (Zygnematophyceae) de duas Áreas de Proteção Ambiental da planície litorânea do norte da Bahia, Brasil. Revista Brasileira de Botânica, 32: 213-232.

Prescott, G.W., Bicudo, C.E.M. \& Vinyard W.C. 1981. A synopsis of North American desmids.
Part II. Desmidiaceae: Placodermae. Section 3. University of Nebraska Press, Lincoln, London.

Ralfs, J. 1848. The British Desmidieae. Reever, London.

Scott, A.M. \& Grönblad, R. 1957. New and interesting Desmids from the southeastern United States. Acta Soc. Sci. Fennica, ser. B. II, 8: $1-62$.

Silva, S.R.V.F. \& Cecy, I.I.T. 2004. Desmídias (Zygnemaphyceae) da área de abrangência da Usina Hidrelétrica de Salto Caxias, Paraná, Brasil, I. Gêneros Cosmarium. Iheringia, série Botânica 59: 13-26.

Sophia, M.G., Dias, I.C.A. \& Araújo, A.M. 2005. Chlorophyceae and Zygnematophyceae from the Turvo State Forest Park, state of Rio Grande do Sul, Brazil. Iheringia, série. Botânica 60: 25-47.

Suárez-Mera, P.A. 1995. Características ecológicas da desmidioflórula de uma região hidrográfica do Sistema Trombetas estado do Pará. Tese de Doutorado, Instituto Nacional de Pesquisas da Amazônia, Fundação Universidade do Amazonas, Manaus.

Taniguchi, G.M., Peres, A.C., Senna, P.A.C. \& Compère, P. 2003. The desmid genera Cosmarium, Actinotaenium and Cosmocladium from an oxbow lake, Jataí Ecological Station (Southeastern Brasil). Syst. Geogr. Plants, 37: 133-159.

Thomasson, K. 1971. Amazonian desmids. Mémoires Institute Royal des Sciences Naturelles de Belgique, ser. 2, 86: 1-57.

Torgan, L.C., Baredo, K.A. \& Fortes, D.F. 2001. Catálogo das algas clorophyta de águas continentaisemarinhasnoestadodoRioGrandedo Sul, Brasil. Iheringia, série Botanica 56: 147-183.

Ungaretti, I. 1981. Desmídias (Zygnemaphyceae) de um açúde do Morro Santana, Porto Alegre, Rio Grande do Sul, Brasil. Iheringia, série Botanica 27: 3-26.

Wehr, J.D. \& Sheat, R.G. 2003. Freshwater Algae of North America. Ecology and Classification. Academic Press, New York.

West, W. \& West, G.S. 1905. A monograph of the British Desmidiaceae. v. 2, The Ray Society, London.

West, W. \& West, G.S. 1908. A monograph of the British Desmidiaceae. v. 3, The Ray Society, London. 